\title{
Correction of raindrop size distributions measured by Parsivel disdrometers, using a two-dimensional video disdrometer as a reference
}

\author{
T. H. Raupach and A. Berne \\ Environmental Remote Sensing Laboratory, School of Architecture, Civil, and Environmental Engineering, \\ École Polytechnique Fédérale de Lausanne (EPFL), 1015 Lausanne, Switzerland
}

Correspondence to: A. Berne (alexis.berne@epfl.ch)

Received: 22 July 2014 - Published in Atmos. Meas. Tech. Discuss.: 19 August 2014

Revised: 21 November 2014 - Accepted: 25 November 2014 - Published: 16 January 2015

\begin{abstract}
The raindrop size distribution (DSD) quantifies the microstructure of rainfall and is critical to studying precipitation processes. We present a method to improve the accuracy of DSD measurements from Parsivel (particle size and velocity) disdrometers, using a two-dimensional video disdrometer (2DVD) as a reference instrument. Parsivel disdrometers bin raindrops into velocity and equivolume diameter classes, but may misestimate the number of drops per class. In our correction method, drop velocities are corrected with reference to theoretical models of terminal drop velocity. We define a filter for raw disdrometer measurements to remove particles that are unlikely to be plausible raindrops. Drop concentrations are corrected such that on average the Parsivel concentrations match those recorded by a 2DVD. The correction can be trained on and applied to data from both generations of OTT Parsivel disdrometers, and indeed any disdrometer in general. The method was applied to data collected during field campaigns in Mediterranean France for a network of first- and second-generation Parsivel disdrometers, and on a first-generation Parsivel in Payerne, Switzerland. We compared the moments of the resulting DSDs to those of a collocated 2DVD, and the resulting DSD-derived rain rates to collocated rain gauges. The correction improved the accuracy of the moments of the Parsivel DSDs, and in the majority of cases the rain rate match with collocated rain gauges was improved. In addition, the correction was shown to be similar for two different climatologies, suggesting its general applicability.
\end{abstract}

\section{Introduction}

The raindrop size distribution (DSD) quantifies the microstructure of rainfall. The DSD describes the statistical distribution of falling drop sizes: it is the number of drops with a given equivolume diameter per unit volume of air. The DSD plays a fundamental role in the analysis of rainfall. Interception of precipitation by vegetation canopies or city environments, erosion of soil through raindrop impact, and pollutant dispersal both on the ground and in the atmosphere are all fields in which the DSD is important (e.g. Uijlenhoet and Sempere Torres, 2006). Knowledge of the DSD is required in order to study the behaviour of electromagnetic waves in the atmosphere, so it is highly relevant to rainfall remote sensing and telecommunication links (Olsen et al., 1978; Jameson and Kostinski, 2001; Uijlenhoet and Sempere Torres, 2006). Moreover, all bulk rainfall variables of interest can be derived as weighted moments of the DSD (e.g. Ulbrich, 1983; Testud et al., 2001). In order to study rainfall microstructure effectively, we require accurate measurements of the DSD.

Disdrometers are instruments that measure the DSD at a point location. There are various types, each with advantages and disadvantages. In this paper we are concerned with the OTT Hydromet particle size and velocity (Parsivel) disdrometer, and the two-dimensional video disdrometer (2DVD) from Joanneum Research. The original Parsivel was by PM Tech Inc. OTT Hydromet purchased the rights to the instrument and redesigned it in 2005; the result was the firstgeneration Parsivel. The second-generation Parsivel ${ }^{2}$ was introduced in 2011, and provided improvements over the firstgeneration model (Tokay et al., 2014). The Parsivel is a laser 
optical disdrometer that uses a sheet of light through which drops fall. The diameter and velocity of a drop is then determined by sensing the shadow it casts and for how long it casts it (Löffler-Mang and Joss, 2000). Parsivels bin drops into classes of velocity and diameter and record the number of drops measured per class over an integration time. Parsivel disdrometers have been shown to be susceptible to errors in the recorded drop concentrations, particularly for small and large drops (Krajewski et al., 2006; Tokay et al., 2013). The Parsivel measurement technique assumes properties of the precipitation that are far more appropriate for rain than for solid precipitation; for example, that particles will be spheroidal, have a horizontal orientation of their major axis, and that only one particle will be in the beam at once (Yuter et al., 2006; Battaglia et al., 2010). The Parsivel is, however, a low cost, durable, and reliable instrument that makes it particularly well-suited for deployment in networks to study the small-scale variability of the DSD (e.g. Tapiador et al., 2010; Jaffrain et al., 2011).

The 2DVD ${ }^{1}$ uses two perpendicular high-speed line-scan cameras, each with an opposing light source, to measure particles from orthogonal angles and thus record their shape (e.g. Thurai and Bringi, 2005; Thurai et al., 2007) as well as their size and velocity (Kruger and Krajewski, 2002; Schönhuber et al., 2008). Information on each individual particle that falls through the measurement area of the 2DVD is recorded. A particle's fall speed is determined by the difference in time between its detection in the two camera planes, which are offset vertically by $6.2-7 \mathrm{~mm}$. Thus, the 2DVD uses no literature-derived estimates for raindrop shape or velocity; these parameters are measured directly (Schönhuber et al., 2008). Some drawbacks of the 2DVD have been noted. In particular, drops with diameters smaller than $0.2 \mathrm{~mm}$ have been found to be unreliably measured (Tokay et al., 2001); Tokay et al. (2013) recommend taking $0.3 \mathrm{~mm}$ as a minimum measured diameter in 2DVD data due to underestimation of drop counts below this diameter. In earlier designs of the instrument, the reliability of measurements decreased with increasing wind speed (Nešpor et al., 2000). This has subsequently been addressed through design improvements (Schönhuber et al., 2007).

Several comparisons between 2DVD and Parsivel disdrometers have been reported on in the literature. In experimental trials the 2DVD has been found to produce better matches to rain gauges than Joss and Waldvogel (Tokay et al., 2001) and Parsivel (Thurai et al., 2011; Tokay et al., 2013) disdrometers. Krajewski et al. (2006) showed that PM Tech Parsivel disdrometers measured higher numbers of small drops $(0.2$ to $0.4 \mathrm{~mm})$ than the 2DVD and generally reported higher rain rates. In a study in Alabama,

\footnotetext{
${ }^{1}$ The 2DVD was called the two-dimensional video distrometer by Schönhuber et al. (2008), to emphasise that the instrument collects information on the distribution of particles. To avoid confusion we use the standard spelling of disdrometer.
}

USA, using first-generation Parsivels, Tokay et al. (2013) found that Parsivel disdrometers were less sensitive to small drops than the 2DVD, and that they overestimated the numbers of drops over $2.44 \mathrm{~mm}$ in diameter, while underestimating the numbers of drops under $0.76 \mathrm{~mm}$ in diameter. Furthermore, they found that Parsivels measured fall velocities lower than the expected terminal fall speeds for drops larger than $2.44 \mathrm{~mm}$ in diameter. Tokay et al. (2013) concluded that inhomogeneous laser beams in first-generation Parsivel disdrometers were the cause of the misestimation of drop counts. Thurai et al. (2011) found that first-generation Parsivels recorded higher mass-weighted mean diameter and rain rate than $2 \mathrm{DVD}$, mostly when the rain rate exceeded $20 \mathrm{~mm} \mathrm{~h}^{-1}$.

Disdrometers can record erroneous measurements due to wind turbulence, splashing, mismatching between cameras (in the case of the 2DVD), multiple drops appearing at the same time, margin-fallers, or external interference from, for example, insects or spiderwebs. Minimal data treatment for disdrometer measurements usually involves removing outlier points by reference to expected terminal fall velocity (e.g. Tokay et al., 2001; Kruger and Krajewski, 2002; Thurai and Bringi, 2005). For example, Tokay et al. (2013) removed drops exceeding $\pm 50 \%$ of the expected terminal fall speed, while Jaffrain and Berne (2011) used a threshold of $\pm 60 \%$ of the expected fall speed. This existing approach removes particles that are obviously erroneous, but it has some shortcomings. By only removing measurements, it does not allow for the fact that the disdrometer may underestimate the number of drops falling. Most importantly, the treatment is based solely on bulk variables such as rain rate, and does not test whether the resulting DSDs after the correction are physically viable.

In this paper we present a correction method for DSD measurements provided by Parsivel disdrometers, using a 2DVD as a reference instrument. The correction is designed to ensure that the DSDs recorded by Parsivel disdrometers are accurate, in terms of both the raw DSD and its moments. The correction method adjusts two properties of the recorded DSDs. First, drop velocities per diameter class are shifted such that the mean velocity per diameter class aligns with the theoretical terminal drop velocity for raindrops of that diameter; these raw measurements can then be screened for implausible measurements. Second, per-diameter-class volumetric drop concentrations are scaled such that they match, in a statistical way, the concentrations measured by a collocated 2DVD.

The rest of this paper is organised as follows: the DSD is introduced in detail in Sect. 2. The data used are described in Sect. 3. Measurement of the DSD and the instruments we are concerned with in this work are discussed in Sect. 4. The correction is introduced in Sect. 5. The results of the correction applied to the data are shown in Sect. 6 for first-generation Parsivels, and in Sect. 7 for Parsivel ${ }^{2}$. The application of 
the technique to another climatology is addressed in Sect. 8. Concluding remarks are made in Sect. 9.

\section{The drop size distribution of precipitation}

On average, during precipitation, $1 \mathrm{~m}^{3}$ of air contains about $10^{3}$ raindrops, with many more small drops than large ones (Uijlenhoet and Sempere Torres, 2006). Small raindrops are close to spherical, but in drops larger than about $1 \mathrm{~mm}$ in diameter, the bottom of the drop flattens out progressively with drop size (Beard and Chuang, 1987; Andsager et al., 1999; Pruppacher and Klett, 2000; Thurai and Bringi, 2005; Thurai et al., 2007). For this reason the size of a raindrop is generally characterised by its equivolume diameter, which is the diameter of a sphere containing the same volume of water as the drop. Raindrops are primarily between 0.1 and $6 \mathrm{~mm}$ in equivolume diameter, and they fall at speeds from 0.1 to greater than $9 \mathrm{~m} \mathrm{~s}^{-1}$ (Uijlenhoet and Sempere Torres, 2006; Roe, 2005), with the terminal fall speed of a drop dependent on its size, plus the atmospheric temperature, relative humidity, and altitude above sea level (Beard, 1976). The volumetric DSD is written $N(D)$, and is the number of raindrops with equivolume diameter $D$ per unit volume of air (Jameson and Kostinski, 2001).

The drop size distribution $N(D)\left(\mathrm{m}^{-3} \mathrm{~mm}^{-1}\right)$ can be described as the total drop concentration multiplied by a probability density function $f(D)$, such that

$N(D)=N_{\mathrm{t}} f(D)$.

The total drop concentration $N_{\mathrm{t}}\left(\mathrm{m}^{-3}\right)$ is the total number of drops falling per cubic metre of air. It is the zeroth moment of the DSD, such that

$N_{\mathrm{t}}=\int_{D_{\min }}^{D_{\max }} N(D) \mathrm{d} D$.

The great power of the DSD comes from the fact that, because the shape and fall velocity of a raindrop can be reliably described once its equivolume diameter is known, all integral rainfall parameters of interest can be derived as weighted moments of the DSD. These are also known as bulk rainfall parameters. Any bulk rainfall parameter $P$ can be written as

$P=a_{P} \int_{D_{\min }}^{D_{\max }} w_{P} D^{p} N(D) \mathrm{d} D$,

where $a_{P}$ and $p$ are constants (Ulbrich, 1985) and $w_{P}$ is a weight that possibly depends upon $D$. For example, the rain rate $R\left(\mathrm{~mm} \mathrm{~h}^{-1}\right)$ is defined from the DSD as

$R=6 \pi 10^{-4} \int_{D_{\min }}^{D_{\max }} N(D) v(D) D^{3} \mathrm{~d} D$, where $v(D)\left(\mathrm{m} \mathrm{s}^{-1}\right)$ is the terminal fall velocity for drops with equivolume diameter $D(\mathrm{~mm})$. Terminal fall velocities in still air can be calculated from the equivolume diameter; popular formulas include those of Atlas et al. (1973), Beard (1976), and Brandes et al. (2002).

The definitions given in this section assume a continuous DSD function of which the integral can be taken. When measured by an instrument, however, the DSD is usually provided as the concentration of drops per discrete class of equivolume diameter. In this case the above equations are modified, such that the integration becomes a sum over all classes, $N(D)$ becomes $N_{i}\left(\mathrm{~mm}^{-1} \mathrm{~m}^{-3}\right)$, the drop concentration for the $i$ th class, and $\mathrm{d} D$ becomes $\Delta D_{i}(\mathrm{~mm})$, the width of the $i$ th class. When the diameter $D$ of drops in a class is required, for example in Eq. (4), we use the centre of the $i$ th diameter class, which we call $D_{i}(\mathrm{~mm})$.

\section{Data}

The Parsivel DSD correction was developed and tested on first-generation Parsivel data collected during two consecutive autumns in Ardèche, France, as part of the Hydrological Cycle in the Mediterranean Experiment (HyMeX ${ }^{2}$, Drobinski et al., 2014). The method was then also tested on secondgeneration Parsivel (Parsivel ${ }^{2}$ hereafter) data collected in the same region in autumn 2013. To test the method in a different climatology and region, we used data from Payerne, Switzerland, using a first-generation Parsivel and the same 2DVD used in the HyMeX campaign. In this section these data sets are briefly described.

\subsection{HyMeX SOPs 2012 and 2013}

Two autumn campaigns in the same region in Ardèche, France, provided the primary data used in this work. The campaigns were special observation periods (SOPs) run between September and November in both 2012 (SOP2012) and 2013 (SOP2013). The field site was a roughly $5 \times 5 \mathrm{~km}^{2}$ area in the Cévennes region; see the map in Fig. 1. Cévennes has a Köppen-Geiger Cfa climate type, which indicates that it has a temperate climate with no dry season and a hot summer (Peel et al., 2007). The town of Montélimar, about $18 \mathrm{~km}$ from the SOP2012 and SOP2013 field area, records an average annual rainfall of $905 \mathrm{~mm}$, with 77 rainy days per year on average (MeteoFrance, 2014). Cévennes experiences Mediterranean rainfall and has a well-defined precipitation maximum in October (Frei and Schär, 1998). It is subject to heavy precipitation events that can produce large rainfall totals (greater than $150 \mathrm{~mm}$ ) in a day (Ricard et al., 2012).

In 2012, seven first-generation Parsivel disdrometers (two of which were collocated) and a 2DVD were deployed. In 2013, the same network was deployed with the addition of two more first-generation Parsivel disdrometers. The 2DVD

\footnotetext{
${ }^{2}$ See http://www.hymex.org
} 


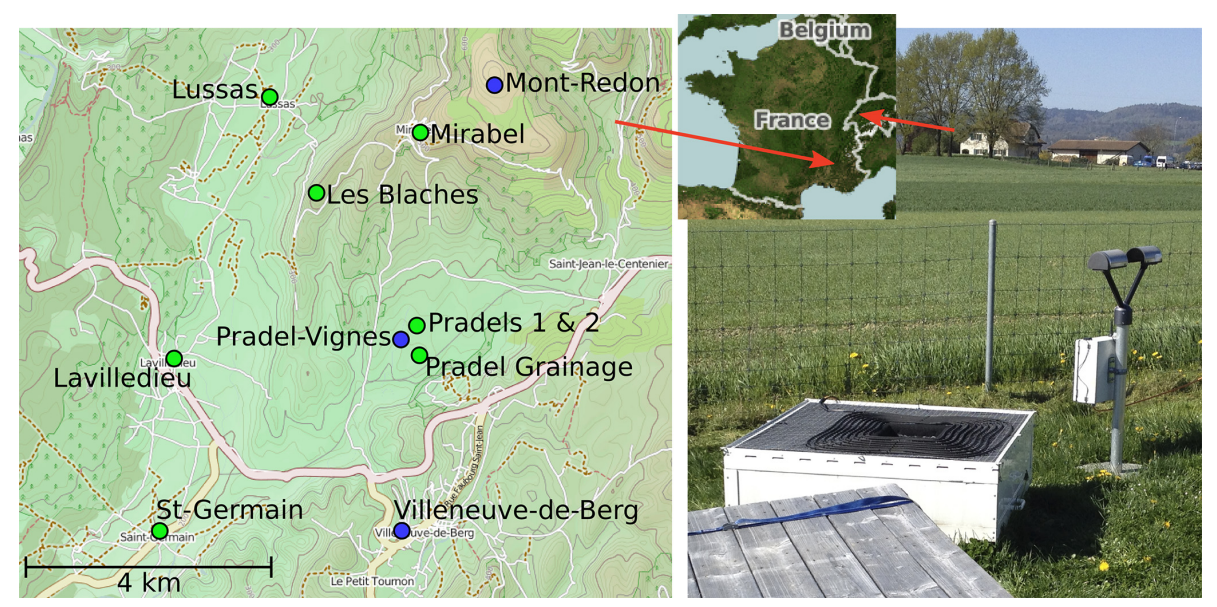

Figure 1. The setup of the field campaigns. For HyMeX, in Ardèche, on the left: Parsivel stations (green) and Parsivel ${ }^{2}$ stations (blue). Montbrun and Pradel Grainage first-generation stations were deployed only in 2013. Pradel was the location of collocated Parsivel firstgeneration stations. Pradel Grainage was the location for both first and second-generation instruments in 2013. Two Parsivel ${ }^{2}$ stations were collocated in Villeneuve-de-Berg. The 2DVD was located at Pradel Grainage. The inset map shows the location of the two field areas. On the right is a picture of the setup for Payerne 2014. Maps ${ }^{\circledR}$ Thunderforest (CC BY-SA, http://www.thunderforest.org/), map data ${ }^{\circledR}$ OpenStreetMap (ODbL, http://www.openstreetmap.org/copyright).

was collocated with a Parsivel and a tipping-bucket rain gauge in 2013. Collocated rain gauge measurements were available for all disdrometers, with the exception of Montbrun in 2013. Furthermore, we used data from a network of five Parsivel $^{2}$ disdrometers that was deployed in the same region during the 2013 campaign. Station information is summarised for all the disdrometers in Table 1 . In this paper we refer to the two campaigns as SOP2012 and SOP2013. For our purposes, the main difference between the setup of the two campaigns is that in SOP2013, there was a Parsivel, Parsivel $^{2}$, and rain gauge collocated with the 2DVD at the Pradel Grainage site. In SOP2012, the closest Parsivel and rain gauge to the 2DVD were at the site of Pradel 1 and Pradel 2, about $480 \mathrm{~m}$ away. For some analyses we combined data from SOP2012 and SOP2013 into a single data set, which we refer to as the "combined SOPs" data set.

Due to a clock error with the 2DVD, a variable clock drift was present in the 2DVD data. During the campaign, Parsivel clocks were synchronised using inbuilt global positioning system (GPS) receivers and were thus more reliable than the 2DVD clock. Adjustments were made to the 2DVD data for SOP2013 in order to synchronise the clocks of the instruments, for events where it was possible to do so. This synchronisation was done manually, by comparing time series of the rain rate from the 2DVD and a collocated Parsivel. The 2DVD time series was shifted forward in time to match the Parsivel time series as closely as possible, at $30 \mathrm{~s}$ temporal resolution. The adjustment was then applied to the series of individual 2DVD drops. Table A1 shows the adjustments made per event in SOP2013, which are between 30 and $60 \mathrm{~s}$. For SOP2012, no adjustments were made because the 2DVD was not collocated with any instruments.

\subsection{Payerne 2014}

To test the method on data collected in a different region and a different climatology, we used data collected in Payerne, Switzerland. Payerne has a Köppen-Geiger Cfb climate type, which indicates that it has a temperate climate, without a dry season, and with a warm summer. It has an average annual rainfall of $891 \mathrm{~mm}$, with an average of 114 rainy days per year (MeteoSwiss, 2013), meaning that the precipitation in Payerne is more evenly spread across the year than in Ardèche. In contrast to the drier summers of Ardèche, Payerne's rainfall is higher during the summer months (MeteoSwiss, 2013). A first-generation Parsivel disdrometer was collocated with a 2DVD in Payerne between April and June 2014. Table 2 shows the station information. In this paper, we describe the development of the Parsivel correction technique by focusing on data from the HyMeX SOP2012 and SOP2013 campaigns. We then discuss the application of the technique to data from Payerne, to examine its applicability to a different climatological region.

\section{Processing of disdrometer measurements}

Disdrometer measurements must be processed to convert raw measurements into more useful forms. In this section we describe the processing of data from the Parsivel disdrometer and 2DVD.

\subsection{Parsivel}

Parsivel disdrometers bin measured particles into particle counts per velocity and diameter class. There are 32 velocity 
Table 1. Disdrometer station information for the HyMeX campaigns, showing the instrument (P1 - first-generation Parsivel, $\mathrm{P} 2$ - Parsivel ${ }^{2}$, 2DVD - two-dimensional video disdrometer), the WSG84 (World Geodetic System 1984) coordinates of each station, its altitude (m) above sea level, the number of hours it recorded liquid precipitation $\left(R>0.01 \mathrm{~mm} \mathrm{~h}^{-1}\right)$ with all quality control flags positive during 2012 (H12) and 2013 (H13), and the total amount (mm) it recorded for those times in 2012 (A12) and in 2013 (A13). Note that hours and amounts are calculated using Parsivel data after the correction has been applied. The station at St-Germain had technical problems in 2013, which accounts for its lower hours and total amount.

\begin{tabular}{llrrrrrrr}
\hline Inst & Name & Lat $\left({ }^{\circ} \mathrm{N}\right)$ & Long $\left({ }^{\circ} \mathrm{E}\right)$ & Alt & H12 & H13 & A12 & A13 \\
\hline P1 & Lavilledieu & 44.5772 & 4.4532 & 227 & 169 & 111 & 252 & 223 \\
P1 & Les Blaches & 44.6008 & 4.4810 & 429 & 148 & 107 & 258 & 210 \\
P1 & Lussas & 44.6123 & 4.4706 & 289 & 117 & 102 & 226 & 181 \\
P1 & Mirabel & 44.6069 & 4.4987 & 496 & 168 & 125 & 260 & 242 \\
P1 & Pradel 1 & 44.5829 & 4.4987 & 278 & 145 & 117 & 259 & 203 \\
P1 & Pradel 2 & 44.5829 & 4.4987 & 278 & 149 & 106 & 286 & 157 \\
P1 & Pradel Grainage & 44.5790 & 4.5011 & 271 & & 105 & & 197 \\
P1 & St-Germain & 44.5551 & 4.4497 & 204 & 158 & 89 & 283 & 97 \\
P2 & Mont-Redon & 44.6141 & 4.5148 & 636 & & 134 & & 219 \\
P2 & Pradel Grainage & 44.5790 & 4.5011 & 271 & & 118 & & 196 \\
P2 & Pradel-Vignes & 44.5801 & 4.4950 & 256 & & 47 & & 128 \\
P2 & Villeneuve-de-Berg & 44.5547 & 4.4954 & 301 & & 111 & & 189 \\
P2 & Villeneuve-de-Berg 2 & 44.5547 & 4.4954 & 301 & & 113 & & 198 \\
2DVD & 2DVD & 44.5790 & 4.5011 & 271 & 129 & 96 & 230 & 199 \\
\hline
\end{tabular}

Table 2. Disdrometer station information for the Payerne 2014 campaign, showing the instrument (P1 - first-generation Parsivel, 2DVD - two-dimensional video disdrometer), the WSG84 coordinates of each station, its altitude $(\mathrm{m})$ above sea level, the number of hours it recorded liquid precipitation $\left(R>0.01 \mathrm{~mm} \mathrm{~h}^{-1}\right)$ with all quality control flags positive, and the total amount $(\mathrm{mm})$ it recorded for those times. SSP stands for Station SwissMetNet Payerne. Note that hours and amounts are calculated using Parsivel data after the correction has been applied. The 2DVD was deployed later than the Parsivel.

\begin{tabular}{llrrrrr}
\hline Inst & Name & Lat $\left({ }^{\circ} \mathrm{N}\right)$ & Long $\left({ }^{\circ} \mathrm{E}\right)$ & Alt & H14 & A14 \\
\hline P1 & SSP & 46.8115 & 6.9424 & 490 & 208 & 263 \\
2DVD & 2DVD & 46.8115 & 6.9424 & 490 & 130 & 84 \\
\hline
\end{tabular}

classes and 32 diameter classes, with varying widths. Parsivels also determine the rainfall intensity (or rain rate), and two status flags: one provides an indication of the type of precipitation being observed (liquid or solid, for example), and another provides information on the quality of the measurement. For example, if the glass in front of the Parsivel's laser beam is dirty and reliable measurements are no longer possible, that will be indicated by a quality flag with value of 2 . Value 0 indicates normal operation, while value 1 indicates dirty glass but that measurements are still possible. Value 3 indicates that the laser is damaged. We make use of these flags to restrict our analysis to high-quality measurements.

The effective sampling area of the Parsivel disdrometer is about $54 \mathrm{~cm}^{2}$, but is different for different diameter classes, due to the fact that the whole drop diameter must be included in the sampling area for the drop to be counted. So-called "margin-fallers" are automatically removed, which reduces the effective sampling area. For the $i$ th class, the sampling area is (Löffler-Mang and Joss, 2000; Battaglia et al., 2010)

$S_{i}^{\text {Pars }}=10^{-6} \times L\left(B-\frac{D_{i}}{2}\right)$,

where $S_{i}^{\text {Pars }}\left(\mathrm{m}^{2}\right)$ is the effective sampling area, $D_{i}(\mathrm{~mm})$ is the class-centre equivolume drop diameter for the $i$ th diameter class, $L(\mathrm{~mm})$ is the length of the Parsivel beam $(180 \mathrm{~mm})$, and $B(\mathrm{~mm})$ is the width of the beam $(30 \mathrm{~mm})$.

Let $C_{v, i}(-)$ be the raw number of particles recorded by the Parsivel for the $v$ th velocity class and the $i$ th equivolume drop diameter class. Let $\Delta t$ (s) be the measurement integration time, $V_{v}\left(\mathrm{~ms}^{-1}\right)$ the class-centre velocity of the $v$ th velocity class, and $\Delta D_{i}(\mathrm{~mm})$ the width of the $i$ th diameter class. Then we can convert the raw number of particles into a per-diameter-class volumetric drop concentration $N_{i}^{\text {Pars }}\left(\mathrm{m}^{-3} \mathrm{~mm}^{-1}\right)$ using

$N_{i}^{\text {Pars }}=\frac{1}{S_{i}^{\text {Pars }} \Delta D_{i} \Delta t} \sum_{v=1}^{32} \frac{C_{v, i}}{V_{v}}$.

It is worth noting that the Parsivel instrument itself calculates and provides an estimate of the rain intensity. In this paper we always refer to the estimate of rain rate provided by the Parsivel as the "Parsivel-derived intensity", to avoid confusion with the DSD-derived rain rate $R$, which is defined by Eq. (4). The values of these two variables are usually very similar, but they are not exactly the same; differences are possibly due to peculiarities of the implemented Parsivel processing algorithm that is not public. 


\subsection{Two-dimensional video disdrometer}

The 2DVD records details of individual drops, including the diameter and velocity of each and the effective sampling area of the instrument at the moment the drop was recorded. For our purposes it is practical to bin the drops into diameter classes. Let $M$ be the number of drops that were recorded within one integration time of length $\Delta t$, and let $S_{j}^{2 \mathrm{DVD}}\left(\mathrm{m}^{2}\right)$ and $V_{j}\left(\mathrm{~m} \mathrm{~s}^{-1}\right)$ be respectively the effective sampling area and fall velocity for the $j$ th recorded particle. Then the $i$ th equivolume diameter class, where the class width is $\Delta D_{i}$ (mm), will have a drop concentration $N_{i}^{2 \mathrm{DVD}}\left(\mathrm{m}^{-3} \mathrm{~mm}^{-1}\right)$ of

$N_{i}^{2 \mathrm{DVD}}=\frac{1}{\Delta D_{i} \Delta t} \sum_{j=1}^{M} \frac{1}{S_{j}^{2 \mathrm{DVD}} V_{j}}$.

While most 2DVD-derived bulk rainfall variables are calculated using this $N_{i}^{2 \mathrm{DVD}}$, the rainfall rate $R\left(\mathrm{~m} \mathrm{~h}^{-1}\right)$ for a given time step can be calculated directly from the individual drop measurements without binning the drops into classes. The rain rate is given by

$R^{2 \mathrm{DVD}}=\frac{6 \pi \times 10^{-4}}{\Delta t} \sum_{j=1}^{M} \frac{D_{j}^{3}}{S_{j}^{2 \mathrm{DVD}}}$,

where $D_{j}(\mathrm{~mm})$ is the equivolume diameter of the $j$ th recorded drop. The difference between the drop-wise rain rate and the rain rate calculated from a binned DSD is very small; in the 2DVD data used in this paper, the mean relative difference between DSD-derived rain rate and rain rate calculated drop-wise was less than $0.5 \%$.

While the classes for the Parsivel disdrometer are predefined, we can choose any class definition for the 2DVD data. For comparisons of drop concentrations with the Parsivel records, we used Parsivel diameter classes for the 2DVD. For computation of the other bulk parameters from 2DVD data we used diameter classes with a constant width of $0.2 \mathrm{~mm}$, corresponding to the resolution of the 2DVD.

\subsection{Criteria for suspicious particles}

Before converting our raw drop counts into per-diameterclass volumetric drop counts, we perform some data processing, the aim of which is to filter out particles recorded by the Parsivels and the 2DVD that are very unlikely to be raindrops. These measurements are assumed to be caused by external interferences such as insects, or droplets of water caught in spiderwebs inside the measurement area. We use simple thresholds to exclude classes of velocity and diameter which are unfeasible. To decide on the values for the thresholds, the 2DVD was used as the reference because it is not as easily affected by these external factors as Parsivel disdrometers.

Drops can only reach a certain size (about $10 \mathrm{~mm}$ ) before they break up into smaller drops due to aerodynamic forces

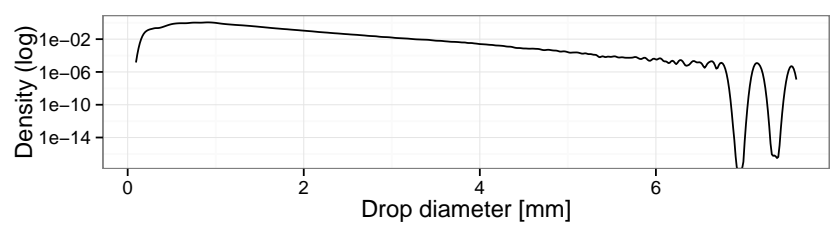

Figure 2. Distribution of drop diameters recorded by the 2DVD in SOP2012 and SOP2013 events, with the $y$ axis on a log scale.

(Pruppacher and Klett, 2000). Figure 2 shows the distribution of drop sizes recorded in rain events from HyMeX (2012 and 2013) by the 2DVD. Table A2 shows the number of drops per diameter class for larger drops. Based on this information, and by looking at the velocity/diameter combinations that the 2DVD hardly ever recorded, we chose a filter that removes a drop with diameter $D(\mathrm{~mm})$ and velocity $V\left(\mathrm{~m} \mathrm{~s}^{-1}\right)$ if any of the following conditions are true:

$$
\begin{aligned}
& D>7.5, \\
& V>v(D)+4, \\
& V<v(D)-3,
\end{aligned}
$$

where $v(D)$ is the terminal velocity for a drop of equivolume diameter $D$ as defined by Beard, 1976. Figure 3 shows the occurrence of velocity/diameter combinations recorded by the 2DVD during the combined SOPs. Figure 5 shows similar plots for sums of drop counts per Parsivel diameter and velocity class, for both the 2DVD and Parsivel. In these figures, the grey area is the region in which drops will be removed. Over the combined SOPs data set, the filter removed $0.2 \%$ of the drops recorded by the 2DVD. This filtering of suspicious records was applied to both Parsivel and 2DVD data before resampling to any different time resolutions. To resample Parsivel records, the mean DSD was found over each new time period and bulk rainfall variables were then calculated from each mean DSD. The Parsivel precipitation type flag was resampled to give an indication of the proportion of the time period for which solid precipitation was recorded. Note that here, solid precipitation refers to any precipitation that does not fit into the Parsivel instrument's criteria for liquid precipitation, which is based on the velocity and size of the particle (see Löffler-Mang and Joss, 2000). The worst quality flag was kept for each resampled time step, to give an indication of whether any low-quality flags were raised during the resampled integration time.

\subsection{DVD as reference instrument}

Given that the 2DVD has previously been shown to produce better matches to independent rain rate measurements than Parsivel (e.g. Tokay et al., 2001; Krajewski et al., 2006), and that it provides higher-resolution DSD measurements than Parsivel, both temporally and in the drop sizes it can discern, we used the 2DVD as the reference instrument for this work. To test the reliability of the 2DVD we compared the 2DVD 


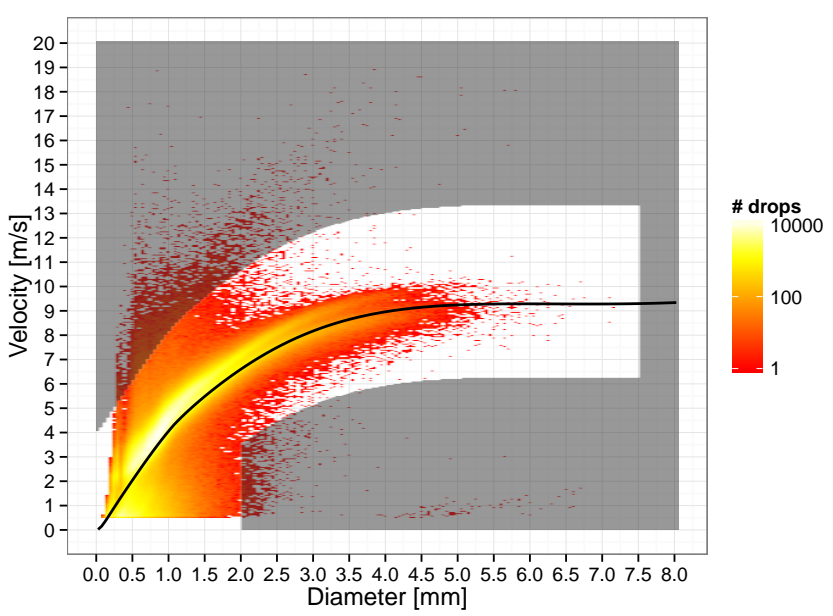

Figure 3. Occurrence of velocity/diameter combinations, with drop counts on a log scale, recorded by 2DVD during the HyMeX campaigns in the autumns of 2012 and 2013. The physical-drop filter is overlaid in grey. The black line indicates the Beard (1976) expected terminal drop velocity.

measurements to collocated rain gauges for the HyMeX SOP2013 campaign. Two separate instruments were collocated with the 2DVD during SOP2013: a Vaisala weather station equipped with a rain cap, and a tipping-bucket rain gauge. We compared the rain rate derived from the 2DVD drop data (Eq. 8) to rain gauge records. To remove solid particles we considered only time steps for which the collocated Parsivel recorded at least $90 \%$ liquid precipitation, and for which the 2DVD and rain gauge both recorded a rain rate greater than or equal to $0.1 \mathrm{~mm} \mathrm{~h}^{-1}$. One outlier time step, for which the 2DVD was only partially working (4 October 2013, 18:00 UTC - Coordinated Universal Time), was removed. The comparisons are shown in Fig. 6.

It is worth noting here the performance statistics we use in this work. In all scatterplots in this paper, the one-to-one line is shown in red dashes, while the blue line indicates the line of best fit found using linear least squares regression, with standard error shaded in grey. The reference instrument is always on the $x$ axis. The regression slope (reg. slope) is the slope of the regression line. For a given time $t$, let the reference value be $R_{t}$ and the observed value be $O_{t}$. Let the total number of time steps be $T$. Then the mean ratio is defined as the reference mean divided by the observed mean:

Mean ratio $=\langle R\rangle /\langle O\rangle$.

Let $E_{t}$ be the difference for the $t$ th time step, defined as $E_{t}=O_{t}-R_{t}$. RMSE is the root mean squared error,

$\mathrm{RMSE}=\sqrt{\frac{\sum_{t=1}^{T} E_{t}^{2}}{T} .}$ $r^{2}$ is the squared Pearson correlation coefficient between reference and observed data sets. Bias is the mean of the differences, $\langle E\rangle$. Relative bias (rel. bias) is the median of the relative errors, a percentage defined as

Rel. bias $=\operatorname{median}\left\{\left(O_{t}-R_{t}\right) / R_{t} \times 100\right\}$.

We are only concerned with liquid precipitation in this paper, so we subset time steps to those in which the Parsivel recorded no solid precipitation (for $5 \mathrm{~min}$ resolution) or at most $10 \%$ solid precipitation (for $1 \mathrm{~h}$ resolution), and for which the Parsivels recorded no non-zero quality status flags. Furthermore, we only compared time steps for which both instruments being compared recorded non-zero rain amounts. We take $0.01 \mathrm{~mm} \mathrm{~h}^{-1}$ as the minimum rain rate the Parsivel can record in one $30 \mathrm{~s}$ integration time. Thus, we use a non-zero rain rate threshold of $0.001 \mathrm{~mm} \mathrm{~h}^{-1}$ at $5 \mathrm{~min}$ resolution and of $8.3 \times 10^{-5} \mathrm{~mm} \mathrm{~h}^{-1}$ at $1 \mathrm{~h}$ resolution. Because each tip of the tipping-bucket rain gauges indicates $0.1 \mathrm{~mm}$ of accumulated precipitation, the minimum rain rate that a rain gauge can measure in $5 \mathrm{~min}$ is $1.2 \mathrm{~mm} \mathrm{~h}^{-1}$, and in $1 \mathrm{~h}$ the minimum is $0.1 \mathrm{~mm} \mathrm{~h}^{-1}$. When comparing to rain gauges, the non-zero rain rate threshold therefore becomes $1.2 \mathrm{~mm} \mathrm{~h}^{-1}$ for $5 \mathrm{~min}$ resolution and $0.1 \mathrm{~mm} \mathrm{~h}^{-1}$ for $1 \mathrm{~h}$ resolution. Because our correction affects the DSD-derived rain rates from the Parsivels, we use the Parsivel-derived intensity when applying the non-zero threshold to Parsivel data. We refer to time steps that satisfy these criteria as those with non-zero liquid DSDs.

The 2DVD showed excellent agreement with the tippingbucket rain gauge and Vaisala weather station, with high correlation coefficients $\left(r^{2}\right.$ at least 0.98$)$ and low bias amounts for both comparisons (absolute bias less than or equal to $0.2 \mathrm{~mm} \mathrm{~h}^{-1}$ ). In both cases the 2DVD tended to slightly underestimate the rain amount given by the other gauge. We conclude, however, that the 2DVD provided reliable measurements of the rain rate. Note that the relative bias between 2DVD and gauge was $-14 \%$, and between 2DVD and Vaisala it was $9 \%$. The difference in these relative biases can be explained largely by differences in measurements of very small rain rates. This is equivalent to the relative bias we observed between two collocated Parsivels (Pradel 1 and Pradel 2) using the same constraints to choose comparison time steps, also at $1 \mathrm{~h}$ resolution, after filtering for unfeasible records (but before any other correction was applied). Using Pradel 1 as reference, the relative bias was $-8 \%(15 \%)$ in 2013 (2012). Using Pradel 2 as reference, the relative bias was $9 \%(-13 \%)$ in 2013 (2012). This means that when we compare Parsivel rain rates to rain gauges or to the 2DVD, we cannot distinguish the level of agreement when the relative bias is less than about $10 \%$, due to instrumental uncertainty. 


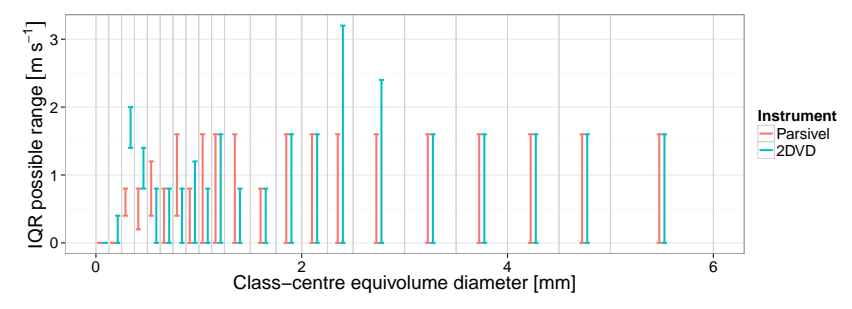

Figure 4. Velocity IQR possible ranges, by Parsivel diameter and velocity class, for mean drop counts for 2DVD and the collocated Parsivel in HyMeX 2013. Only time steps for which both instruments recorded a value and the Parsivel-recorded liquid rain were included. The grey vertical bars indicate the Parsivel diameter class boundaries. Above the 21st diameter class (drops above $6 \mathrm{~mm}$ ), there were not enough drops to meaningfully calculate a velocity range; for this reason the plot is truncated to $6 \mathrm{~mm}$.

\section{Correction of Parsivel DSDs}

The correction of Parsivel DSDs is made in two steps. The two steps were chosen so that both the velocity and diameter measurements made by Parsivel disdrometers are addressed. First, the raw Parsivel data is corrected so that per-diameterclass mean velocities match the expected terminal velocity for each class. At this point the raw data can be screened for unfeasible measurements as described in Sect. 4.3. Second, a per-diameter-class adjustment factor is applied to Parsivel classes, in order to make the drop size distribution match, in a statistical way, that recorded by a 2DVD. This adjustment of drop concentrations in effect changes the drop equivolume diameters measured by the Parsivel. In this section we address each correction in turn.

\subsection{Correction of per-diameter-class drop velocities}

Figures 3 and 5 show the density of particles recorded at each diameter/velocity combination, by the 2DVD and Parsivel disdrometers. Both the 2DVD and Parsivel record drops at a range of velocities for a given equivolume diameter or diameter class. In these plots, the black line is the expected terminal velocity per drop diameter, calculated using the method of Beard (1976). The 2DVD recorded the highest concentrations of drops on and very near the expected terminal velocities. Indeed in SOP2013, for time steps for which the nearest Parsivel recorded liquid precipitation, the bias between expected terminal velocity and velocity recorded by the 2DVD was $0.04 \mathrm{~m} \mathrm{~s}^{-1}$ and the relative bias was $2 \%$ (over the combined SOPs the bias was $0.2 \mathrm{~m} \mathrm{~s}^{-1}$ and relative bias was $6 \%$ ). We hence consider the terminal fall velocity from Beard (1976) as the reference value for fall velocity. The Parsivel tends to overestimate the velocities of small drops.

To correct the velocities in the Parsivel data, we take the set of recorded velocities for each drop diameter class, and shift the values such that the mean velocity is equal to the expected terminal velocity as calculated by the algorithm of
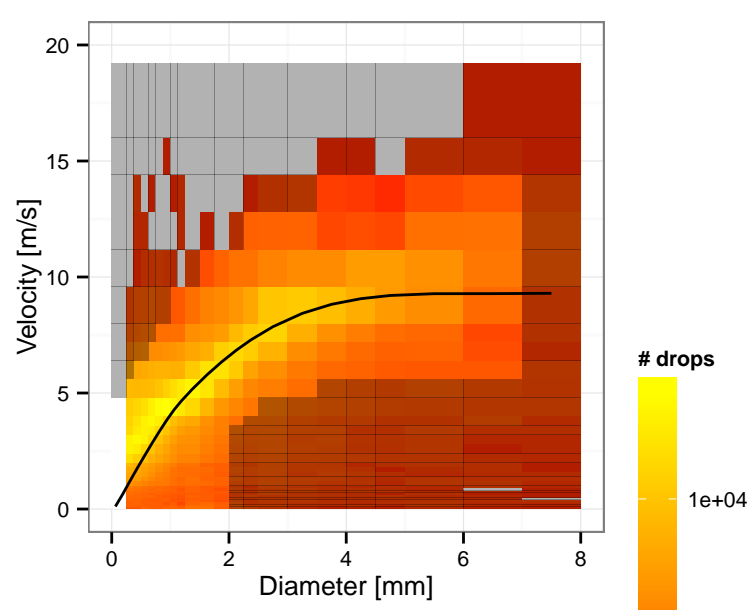

(a) Parsivel

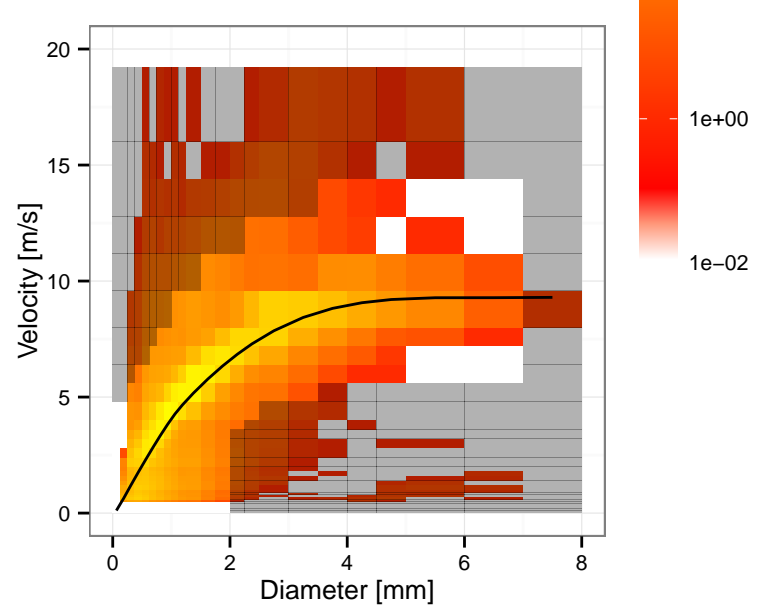

(b) 2DVD

Figure 5. Sum of raw drop occurrences per Parsivel class, for the 2012 and 2013 campaigns. Parsivel counts are summed at stations Pradel 1 (for 2012) and Pradel Grainage (for 2013). The filtered areas are overlaid in grey. The black line is the expected terminal drop velocity calculated by Beard (1976). Drop counts are specified by colour on a log scale.

Beard (1976). Because the velocity classes do not have constant width, the classes are first subsampled into classes of width $0.1 \mathrm{~m} \mathrm{~s}^{-1}$, then shifted and regrouped into the original class sizes. Except when some drops were counted in very low-velocity classes and are shifted out of the valid velocity range, the number of drops per diameter class remains the same before and after the velocity shift. An example plot of drop counts per velocity and diameter class before and after the velocity shift is shown in Fig. 7. The velocity shift is equivalent to shifting each column up or down such that the mean velocity for each column (which is usually close to the brightest point) aligns with the line that indicates the expected terminal velocity. As an example, for the average drop counts per velocity and diameter class for SOP2013, using the Parsivel at Pradel Grainage, the mean shift required 


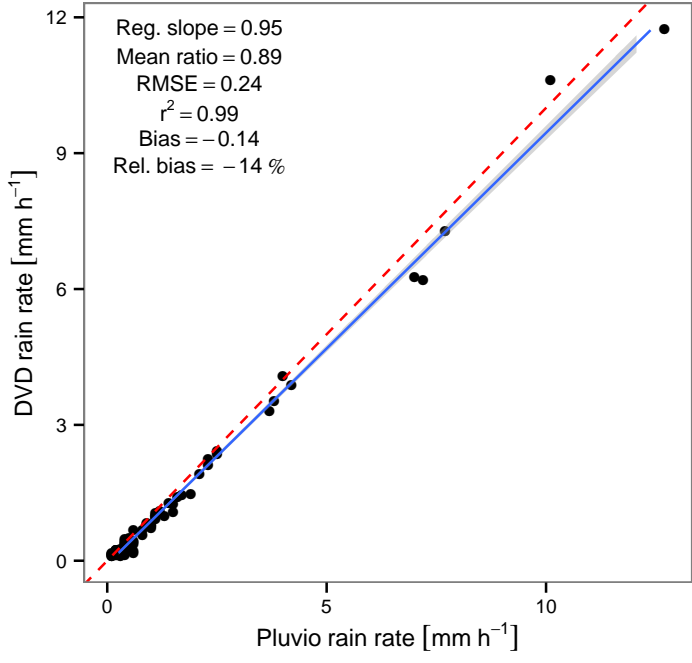

(a) Pluvio to 2DVD, 2013.

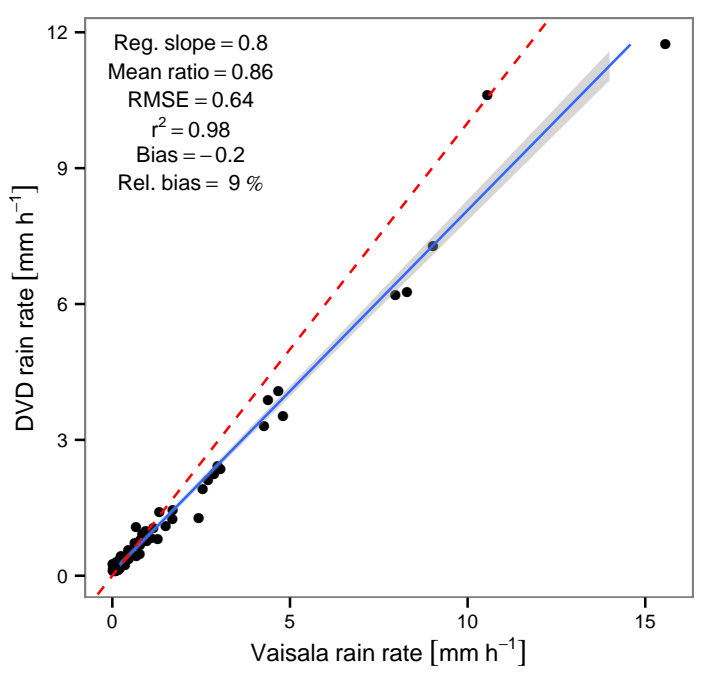

(b) Vaisala to 2DVD, 2013.

Figure 6. Scatterplots showing the comparison between the 2DVD and (a) a collocated tipping-bucket rain gauge (Pluvio), and (b) a collocated Vaisala weather station. Time steps compared are at $1 \mathrm{~h}$ resolution from HyMeX SOP2013, and include only those times for which the collocated Parsivel recorded a Parsivel-derived rain rate $\geq 0.1 \mathrm{~mm} \mathrm{~h}^{-1}, \leq 10 \%$ of the time step was marked as solid precipitation, and for which both the 2DVD and gauge recorded a rain rate $\geq 0.1 \mathrm{~mm} \mathrm{~h}^{-1}$.

per diameter class from 0 to $5 \mathrm{~mm}$ was $-0.29 \mathrm{~m} \mathrm{~s}^{-1}$. Once the velocities are corrected in the raw Parsivel data, any suspicious particles are removed using the criteria shown in Sect. 4.3, and the volumetric drop concentrations per diameter class are found using Eq. (6). This correction and filtering was applied before resampling to any lower time resolutions.

Figure 4 shows a comparison between the interquantile ranges (IQRs) of the recorded velocities, by diameter class. We calculated the mean drop counts per Parsivel velocity and diameter class for SOP2013, for 2DVD and Parsivel. We then

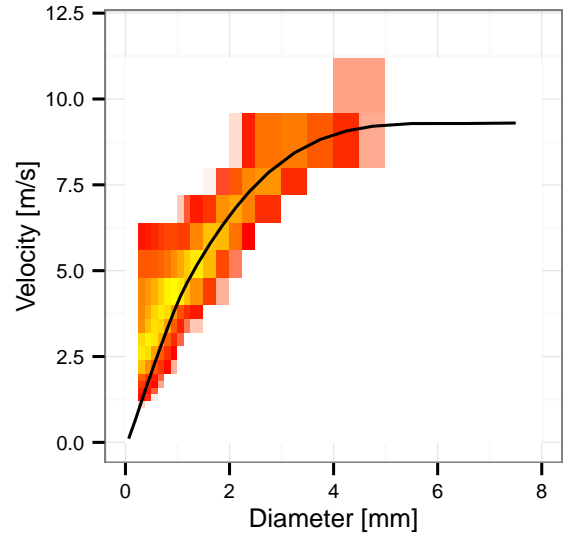

(a) Before velocity correction.

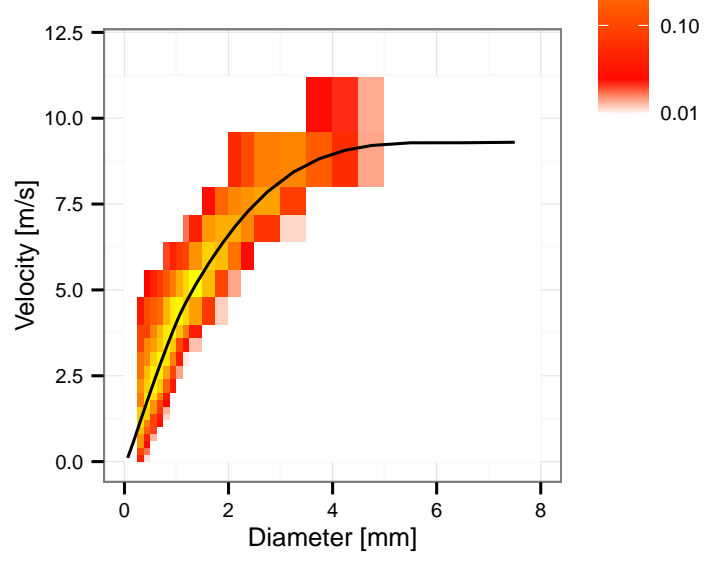

(b) After velocity correction.

Figure 7. An example of the velocity correction. Average drop counts (on a log scale) for liquid rain from the Parsivel at Pradel Grainage for SOP2013, shown (a) before the velocity correction and (b) afterwards.

applied the velocity correction to the Parsivel drop counts, and calculated the velocity class quantiles, weighted by the drop counts per diameter class, for each set. Given that the velocity classes can be quite large, it is possible that the quantiles both fall within one velocity class; in this case, the IQR could be between 0 and the width of the velocity class. We calculated the minimum and maximum possible IQR range for each diameter class. The plot shows that when binned into the Parsivel velocity classes, the spread of velocities was of the same order of magnitude between the two instruments. We conclude that to correct the velocities measured by Parsivel, it is sufficient to shift the mean velocity closer to the expected terminal velocity as described above, then remove suspicious particles (see Eqs. 9, 10, and 11).

\subsection{Correction of diameter-class concentrations}

We now turn to correcting the drop concentrations per diameter class with reference to the 2DVD. Let $P(i)$ be the ratio 
Table 3. Calibrated first-generation Parsivel correction factors for Parsivel-derived intensity classes for the SOP2013 campaign. Each row contains the class number, the centre equivolume diameter for the class $\left(D_{i}\right)$, and the calibrated factors $P(i)$ for each class of Parsivel-derived intensity. Intensity class boundaries are provided in millimetres per hour $\left(\mathrm{mm} \mathrm{h}^{-1}\right)$.

\begin{tabular}{lrrrrr}
\hline Class $(i)$ & $D_{i}(\mathrm{~mm})$ & {$[0,0.5)$} & {$[0.5,1)$} & {$[1,2)$} & {$[2,200)$} \\
\hline 3 & 0.31 & 0.05 & 0.06 & 0.09 & 0.12 \\
4 & 0.44 & 0.12 & 0.15 & 0.24 & 0.28 \\
5 & 0.56 & 0.38 & 0.44 & 0.63 & 0.66 \\
6 & 0.69 & 0.48 & 0.54 & 0.71 & 0.85 \\
7 & 0.81 & 0.70 & 0.77 & 0.95 & 1.13 \\
8 & 0.94 & 0.73 & 0.74 & 0.97 & 1.09 \\
9 & 1.06 & 0.84 & 0.84 & 1.03 & 1.26 \\
10 & 1.19 & 0.90 & 0.84 & 1.04 & 1.27 \\
11 & 1.38 & 0.84 & 0.81 & 1.00 & 1.21 \\
12 & 1.62 & 0.75 & 0.71 & 0.88 & 1.03 \\
13 & 1.88 & 0.74 & 0.57 & 0.77 & 0.96 \\
14 & 2.12 & 0.66 & 0.54 & 0.71 & 0.88 \\
15 & 2.38 & 0.51 & 0.56 & 0.63 & 0.83 \\
16 & 2.75 & 0.47 & 0.45 & 0.47 & 0.77 \\
17 & 3.25 & 0.42 & 0.46 & 0.39 & 0.71 \\
18 & 3.75 & 0.47 & & 0.46 & 0.53 \\
19 & 4.25 & & & & 0.43 \\
20 & 4.75 & & & & 0.20 \\
21 & 5.50 & & & & 0.42 \\
\hline
\end{tabular}

of 2DVD drop concentration to Parsivel drop concentration, defined such that for the $i$ th equivolume diameter class with centre-diameter $D_{i}(\mathrm{~mm})$, at any given time step,

$P(i)=\frac{N_{i}^{2 \mathrm{DVD}}}{N_{i}^{\text {Pars }}}$.

$P(i)$ is thus the correction factor for that time step: when the Parsivel drop concentration for class $i$ is multiplied by $P(i)$ it will match the 2DVD drop concentration for class $i$. To "train" the correction for a given data set, we find median values of $P(i)$ per class of Parsivel-derived rain intensity. Parsivel-derived intensity is used as it is a measurement of the rain intensity that is always available with Parsivel disdrometers, and is independent of our DSD correction. It is hence easily accessible to all potential users. The result is a collection of correction factors for each Parsivel-derived intensity class. When Parsivel records are multiplied by these correction factors, the per-diameter-class drop counts are scaled to match the corresponding 2DVD drop counts.

To explain the correction in more detail, we take as an example the HyMeX 2012 and 2013 SOPs and show each step of the correction calibration. We used data from SOP2013 to train the correction, because there was a Parsivel collocated with the 2DVD at Pradel Grainage in that campaign. We used a time resolution of $1 \mathrm{~h}$, in order to increase the chance of a time step sampling large drops, and in order to smooth outliers. Assuming the obtained correction is not de-

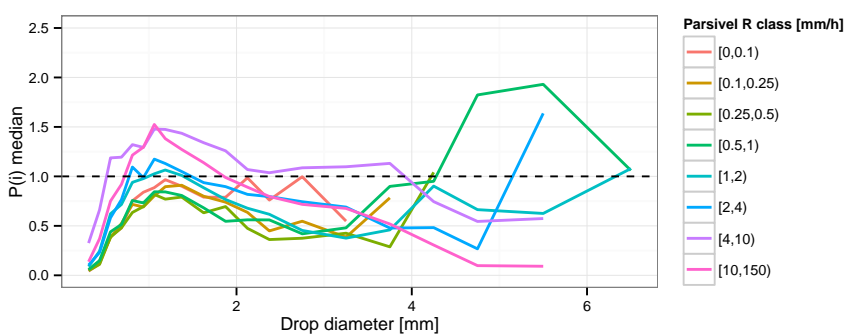

Figure 8. Median $P(i)$ values classed by Parsivel-derived intensity.

pendent on the temporal resolution, it will be applied at resolutions higher than $1 \mathrm{~h}$ in order to have reliable Parsivel DSD measurements for studies of small-scale DSD variability. A strict set of criteria was used to choose which time steps the comparison should be performed on. We used time steps for which the 2DVD and the collocated Parsivel recorded a nonzero liquid DSD. For all of SOP2013 there were 234 such time steps, corresponding to $234 \mathrm{~h}$ of rainfall over which we trained the correction factors. For each valid time step, we compared the mean DSD recorded by the 2DVD and collocated Parsivel.

Values of $P(i)$ were calculated for each time step in the training set, by comparing the Parsivel DSD to the 2DVD DSD. The result is a distribution of $P$ values for each drop diameter class. To investigate the effect of rain intensity on the values of $P(i)$, we divided the time steps into classes of intensity, using the Parsivel-derived intensity modelled by the sensor. The median $P(i)$ values of each intensity and diameter class are shown in Fig. 8. There is clearly a dependency between the values in the $P(i)$ curve and the rain intensity.

The most notable feature of Fig. 8 is that the numbers of small drops (under about $0.7 \mathrm{~mm}$ ) were overestimated by the Parsivel. For these classes, the values of $P(i)$ are low, indicating that the Parsivel drop counts need to be scaled down to match the corresponding 2DVD drop counts. For low rain rates, below $1 \mathrm{~mm} \mathrm{~h}^{-1}$, the Parsivel overestimated drop counts in all classes up to $4 \mathrm{~mm}$. Note that large drops are very rare in these rain rate classes and, as we will see, the values of $P(i)$ are more reliable for smaller drop sizes. We identified groups of behaviour of $P(i)$ by ranges of Parsivel-derived intensity, and thus divided the intensities into four classes for ranges $[0,0.5),[0.5,1),[1,2)$ and $[2,200) \mathrm{mm} \mathrm{h}^{-1}$. Using these ranges as the class definitions for Parsivel-derived intensity, we obtained distributions of $P(i)$ per drop diameter and Parsivel-derived intensity class that are shown in Fig. 9. The distributions are over all time steps and they get larger as the drop diameter increases, which shows that there was much more uncertainty in the correction factors for large diameters than for small diameters.

Across these rain rate classes there was a tendency for the Parsivel to overestimate the numbers of drops smaller than $0.81 \mathrm{~mm}$ in diameter and greater than $1.88 \mathrm{~mm}$ in diameter, 
Table 4. Time series statistics per moment, comparing Parsivel data (at Pradel Grainage) before (bef.) and after (aft.) the correction is applied to the 2DVD, at $5 \mathrm{~min}$ resolution, for event times. The 2DVD is taken as the reference. Units of bias and RMSE are per cubic metres per millimetre $p\left(\mathrm{~m}^{-3} \mathrm{~mm}^{p}\right)$ where $p$ is the moment order. R.b. stands for relative bias.

\begin{tabular}{rrrrrrrrr}
\hline Moment & Bias bef. & Bias aft. & R.b. bef. & R.b. aft. & RMSE bef. & RMSE aft. & $r^{2}$ bef. & $r^{2}$ aft. \\
\hline 0 & 113.21 & 11.01 & 139.53 & 15.70 & 197.46 & 43.82 & 0.57 & 0.91 \\
1 & 51.00 & 9.58 & 87.08 & 18.18 & 89.59 & 36.83 & 0.77 & 0.93 \\
2 & 30.07 & 9.59 & 67.49 & 21.05 & 54.46 & 41.06 & 0.93 & 0.94 \\
3 & 32.21 & 12.27 & 63.90 & 26.31 & 69.92 & 62.65 & 0.96 & 0.95 \\
4 & 69.43 & 22.52 & 66.18 & 32.88 & 213.84 & 131.01 & 0.95 & 0.95 \\
5 & 218.98 & 62.88 & 79.25 & 41.28 & 831.12 & 374.18 & 0.93 & 0.93 \\
6 & 818.32 & 245.64 & 97.61 & 49.48 & 3481.05 & 1446.36 & 0.90 & 0.89 \\
7 & 3402.98 & 1176.15 & 123.17 & 61.57 & 15604.67 & 7069.59 & 0.85 & 0.82 \\
\hline
\end{tabular}

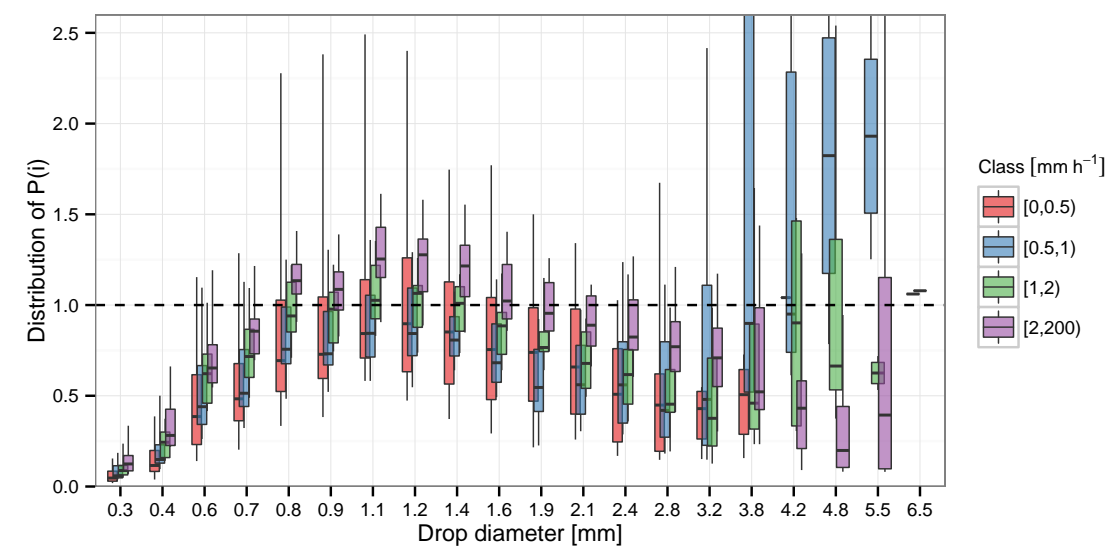

Figure 9. Distributions of $P(i)$ values classed by Parsivel-derived intensity. The correction factors used are the medians of the distributions. The boxes show the interquartile ranges while lines show the 10-90\% quantiles of each distribution. The $y$ axis is cut at 2.6 .

with the best performance occurring in the $1-2 \mathrm{~mm}$ drop diameter range. For rain rates above $2 \mathrm{~mm} \mathrm{~h}^{-1}$, the Parsivel more closely matched the 2DVD and indeed underestimates the numbers of drops between about 0.8 and $1.6 \mathrm{~mm}$ in diameter.

To train the correction factors, we randomly selected sets of $80 \%$ of the valid training time steps. To determine the impact of sampling effect, we reran the calibration 100 times with different randomly chosen calibration time steps, taking the median of the per-class $P(i)$ distribution each time, and recording the range of resulting values. These ranges are shown per Parsivel-derived intensity class in Fig. 10. We see that the sampling effect for small drops was very small, but that it was larger for larger drop size classes. To ensure a more robust correction, we want to only apply the correction to drop diameter classes for which the training sampling effect (the spread) on $P(i)$ is small. However, in order for the correction to affect all moments of the DSD it is important that it is applied to larger drops as well as smaller ones. We decided to apply a threshold on the spread of the sampling effect. The correction was kept for increasing drop diameters until the sampling effect first surpassed this threshold.
There are hence two threshold values that must be chosen to train correction factors. The first is the minimumallowed volumetric drop concentration for which 2DVD and Parsivel classes will be compared; let this threshold be $Q$ $\left(\mathrm{mm}^{-1} \mathrm{~m}^{-3}\right)$. The second threshold is the maximum-allowed spread in values of $P(i)$ over 100 training iterations of the filter; let this threshold be $A$. $Q$ was set to $1 \times 10^{-5}$ and acted simply to stop diminishingly small drop concentrations from adversely affecting the correction calibration. $A$ was set to 0.7 . The spread was also required to be larger than $1 \times 10^{-6}$, to ensure enough samples were available to give a representative calibration for each diameter class. A sensitivity analysis showed that the values of $Q$ and $A$ did not affect greatly the outcome of the calibration, so long as $Q$ was low enough and $A$ was large enough to allow for sampling and therefore correction of larger drops sizes.

To derive the final correction factors we iterated over 100 sets of training time steps, selecting randomly $80 \%$ of the available times for each iteration. The per-diameter and perintensity class correction factor is the mean value of $P(i)$ medians for each class over all iterations. The calibrated correction factors for SOP2013 are shown in Table 3. The largest drop diameter class affected by the correction was the 21 st 


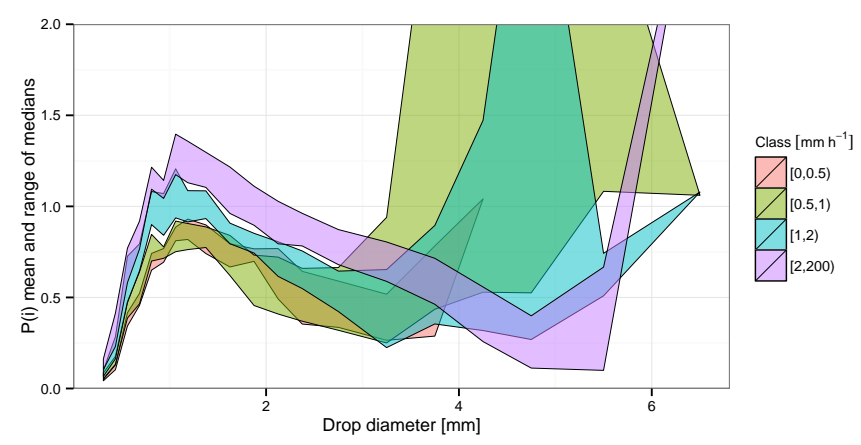

Figure 10. Sampling effect per diameter class, for different classes of Parsivel-derived intensity. The coloured regions represent the minimum and maximum median $P(i)$ per equivolume drop diameter class observed over 100 iterations. The $y$ axis is cut at 2.0.

Parsivel class, with a centre size of $5.5 \mathrm{~mm}$. Drops up to the 17th class (class-centre diameter $3.25 \mathrm{~mm}$ ) are corrected no matter the Parsivel-derived intensity. To apply the correction, each time step was taken separately and, depending on the Parsivel-derived intensity of the time step, the appropriate scaling factors were applied to each equivolume drop diameter amount.

The correction ensures that the corrected DSD more closely matches the DSD recorded by the 2DVD. For example, for the HyMeX SOP2013 data, Fig. 11 shows the distributions of $P(i)$ after the correction, for one example validation set of $20 \%$ of the $1 \mathrm{~h}$ time steps in SOP2013. After the correction the DSD much more closely matched that of the 2DVD, especially for small drop diameter classes. For larger drops of greater than about $3 \mathrm{~mm}$ the match was not as close, but note this is $20 \%$ of the data and sampling effect changes large drop comparisons much more than small ones. The fact that the large drops differed from the $1: 1$ line reflects the difficulty in training a correction for classes in which there are not many drops to use as a training set, and demonstrates why we chose to train on $1 \mathrm{~h}$ time steps and to use the mean $P(i)$ values over many iterations.

\section{Drop concentration correction results}

In this section we explore the effect of the correction on the moments of the DSD, including the derived rain rate. Our goal in this work is to have reliable DSD measurements from networks of Parsivel disdrometers, in order to be able to study the small-scale variability of the DSD in space and time. We are therefore interested in higher time resolutions than the $1 \mathrm{~h}$ resolution we used to train the correction factors. Recall that the choice of $1 \mathrm{~h}$ resolution for the training set was made to increase the numbers of sampled large drops, but that we aim to have a correction that is independent of the time resolution. We thus applied the trained correction to $5 \mathrm{~min}$ time resolution data to evaluate its effects, for all

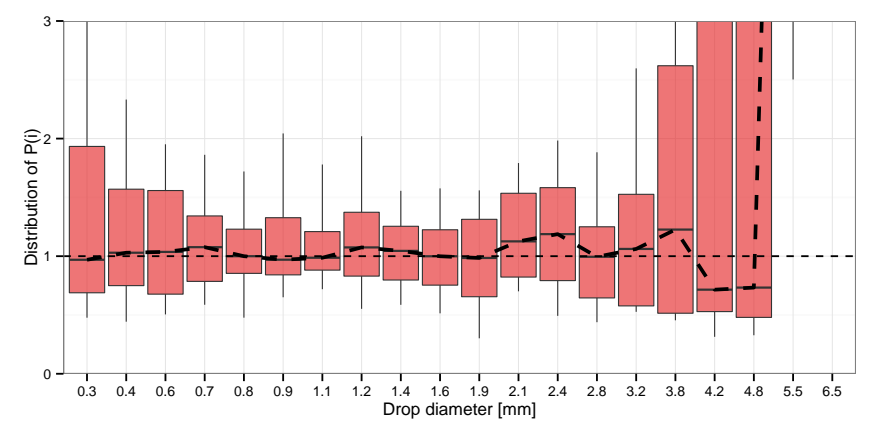

Figure 11. The distributions of $P(i)$ values for the corrected DSD, on an example set of validation time steps from SOP2013, and for all classes of Parsivel-derived intensity, for the Parsivel collocated with the 2DVD. The $y$ axis is cut at 3 .

first-generation Parsivels in the SOP2013 campaign. We also applied the correction to data from SOP2012, as an independent validation data set, and to the combined SOPs. Recall that because we are only interested in liquid precipitation, we subset the available time steps for each Parsivel station to those that contained no Parsivel warning flags regarding data quality, and no solid precipitation markers, and we only compared time steps for which both instruments being compared measured non-zero rain rates.

\subsection{DSD moments}

To demonstrate the effect of the Parsivel DSD correction on the moments of the DSD, we compare the first seven moments of the DSD recorded by the 2DVD, to the same moments derived from Parsivel DSDs before and after the correction is applied. For these comparisons we used HyMeX SOP2013 event time steps at 5 min resolution, and the Parsivel collocated with the 2DVD at Pradel Grainage. Comparisons of moments of orders $0,1,4$, and 6 are displayed in Fig. 12, Q-Q plots for these moments are shown in Fig. 13, and time series statistics are shown in Table 4 . We see from the densities and Q-Q plots that the correction shifted the distributions of all the moments towards those of the 2DVD. The statistics show an improvement in the relative bias of all moments, by a maximum of $124 \%$ for moment zero and a minimum of $33 \%$ for moment four. RMSE was improved for all moments. $r^{2}$ was improved for moments of orders 0,1 , and 2 , and remained very similar for higher moments. These results demonstrate that the correction improves Parsivel DSDs at high temporal resolution even when it is trained from $1 \mathrm{~h}$ DSD spectra.

\subsection{Effect on rain rates}

Having confirmed that the correction shifts the densities of the DSD moments towards those of the 2DVD, we used independent instruments - collocated tipping-bucket rain gauges - to test the effect of the correction on the rain rates produced 


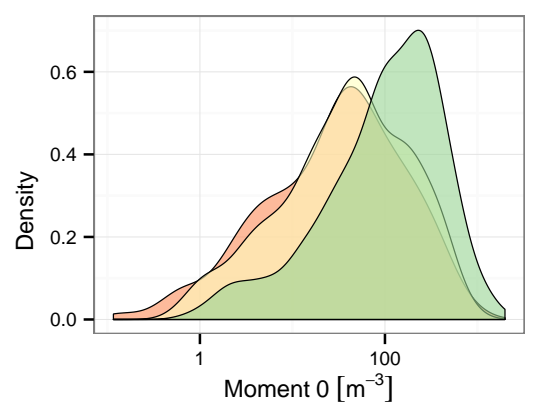

(a)

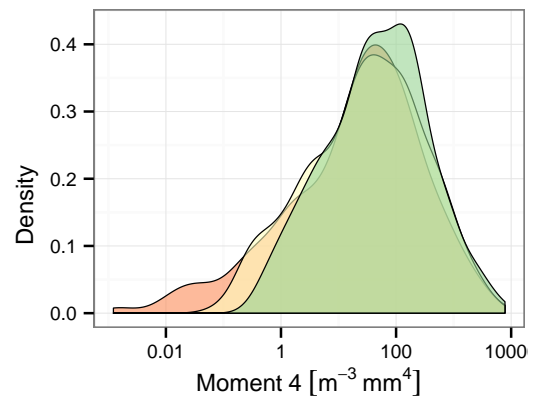

(c)

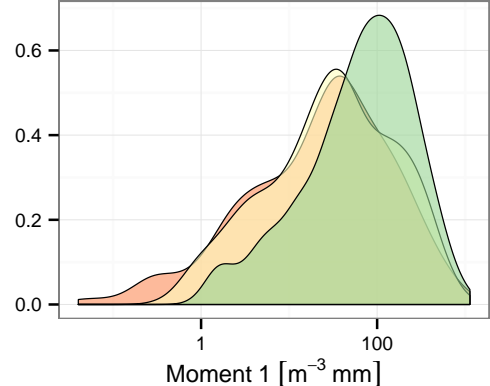

(b)

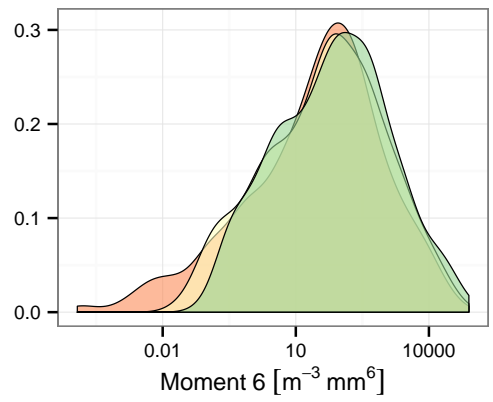

(d)

Figure 12. The effect of the correction on DSD moments (a) 0 and (b) 1, (c) 4, and (d) 6, showing the densities of the Parsivel-derived DSD moments before and after the correction was applied, and the 2DVD moments, for HyMeX SOP2013 event time steps at Pradel Grainage. The $x$ axis has a log scale.

by Parsivel DSDs. Two of the rain gauges provided measurements that we considered to be suspicious. The station at Mirabel-Pradel-Ferme-2, which is physically closest to our Parsivels Pradel 1 and Pradel 2, produced a marked overestimate of the rain amounts compared to those Parsivels, the 2DVD, and the rain gauge at Mirabel-Pradel-Ferme-1. For this reason we used Mirabel-Pradel-Ferme-1 as the reference gauge at this location. Mirabel-Pradel-Ferme-1 was located approximately $12 \mathrm{~m}$ away from Mirabel-Pradel-Ferme2. Similarly, the rain gauge at Lavilledieu-Ecole- 2 was physically closest to our Parsivel at Lavilledieu but, for a period of $1.5 \mathrm{~h}$ on 18 September 2012, this rain gauge produced rain rates that were markedly smaller than the rain rates produced by our Parsivel and the nearby rain gauge LavilledieuEcole-1. This gauge, which was approximately $12 \mathrm{~m}$ away, provided measurements that more closely matched the Parsivel during this time. We thus used Lavilledieu-Ecole-1 as the reference rain gauge for this station.

We compiled performance statistics for each of the firstgeneration Parsivel stations, before and after the correction was applied, for a $5 \mathrm{~min}$ time resolution. As an example, Fig. 14 shows a scatterplot of rain rates compared to a collocated rain gauge for Pradel 1, the Parsivel that was closest to the 2DVD and deployed in both 2013 and 2012, for $5 \mathrm{~min}$ time resolution across both campaigns. The statistics for this station show that the correction produced a clear improvement in the rain rate; the relative bias was reduced by $12 \%$, the mean ratio and regression slope were both closer to 1 and the RMSE was reduced.

Given that the correction was trained only on SOP2013 data, it makes sense to look at the results from SOP2012 and SOP2013 separately as well as together. For SOP2012 only, the performance effects per statistic are shown in Table 5. For SOP2013 only, the performance effects are shown in Table 6. The differences shown are between the performance statistics after the corrections (velocity and concentration) had both been made, minus the statistics when no correction had been made. The before and after sets were both screened to remove implausible measurements. For SOP2012, the correction improved the RMSE, bias, and relative bias at four of the seven stations. At two of the stations (Pradel 1 and Mirabel) the performance was hardly affected by the DSD correction. At the remaining two stations (Lussas and Lavilledieu) the relative bias was degraded, leaving the final relative bias at these stations as -10 and $-9 \%$ respectively; both these relative biases are close to the instrumental variability we observed in Sect. 4.4. Recall that the 2DVD slightly underestimated the rain rate with respect to collocated gauges. For SOP2013, the RMSE and bias were improved at six of eight stations, relative bias was improved at seven of eight stations, and $r^{2}$ was hardly changed. The remaining station (Mirabel) showed a degradation of relative bias to an after-correction relative bias of $-20 \%$. At Mirabel, the Parsivel was placed on the edge of 


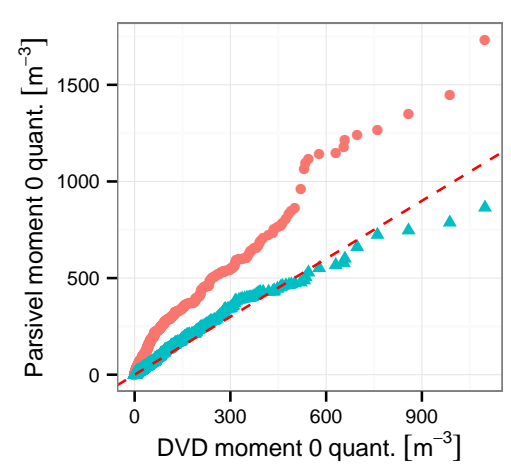

(a)

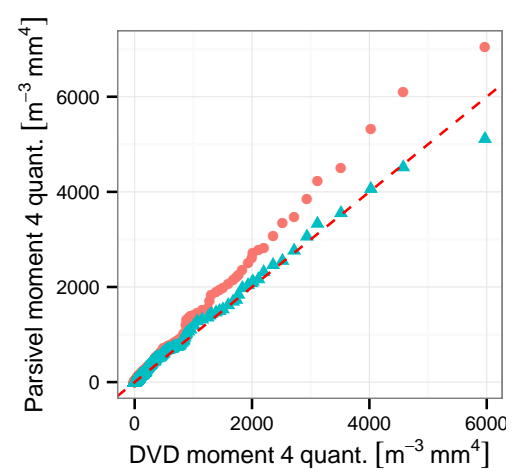

(c)

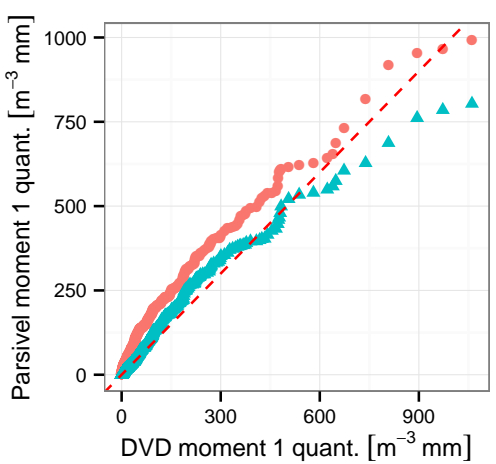

(b)

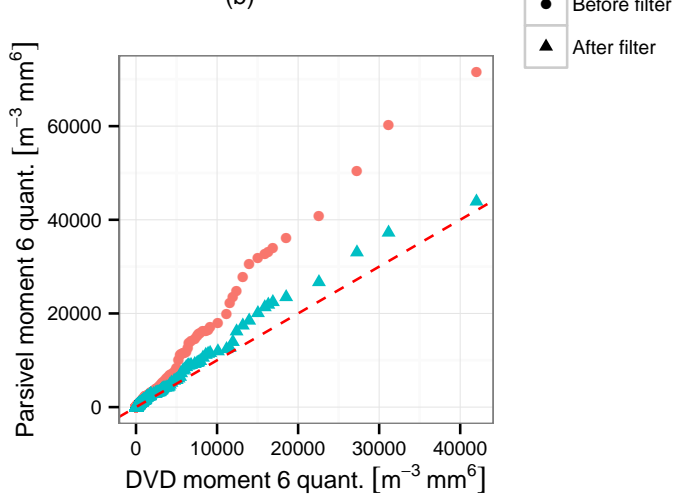

(d)

Figure 13. Quantile-to-quantile plots showing the effect of the correction on Parsivel DSD moments (a) 0 , (b) 1 , (c) 4, and (d) 6 , by comparing to the 2DVD moments, for HyMeX SOP2013 event time steps at Pradel Grainage.

Table 5. Performance effects of the proposed correction on Parsivel data, and stations on which comparisons were performed, for SOP2012 only at $5 \mathrm{~min}$ time resolution. $N$ is the number of time steps on which comparison was possible (high quality, liquid precipitation only). $\Delta$ RMSE and $\Delta \mid$ bias $\mid$ are in units of millimetres per hour, while $\Delta \mid$ r.bias $\mid$ is a percentage.

\begin{tabular}{llrrrrr}
\hline Parsivel & Pluvio & $\Delta$ RMSE & $\Delta \mid$ bias $\mid$ & $\Delta \mid$ r.bias $\mid$ & $\Delta r^{2}$ & $N$ \\
\hline Mirabel & Mirabel-Mairie & 0.660 & 0.532 & 1.032 & 0.003 & 271 \\
Lussas & Lussas-Salle-Polyvalente & 0.362 & 0.454 & 9.980 & -0.002 & 291 \\
St-Germain & Saint-Germain-Ecole & -0.092 & -0.252 & -7.427 & -0.011 & 655 \\
Lavilledieu & Lavilledieu-Ecole-2 & 0.316 & 0.378 & 5.760 & -0.005 & 641 \\
Les Blaches & Mirabel-Les-Blaches & -0.212 & -0.512 & -10.610 & -0.006 & 299 \\
Pradel 1 & Mirabel-Pradel-Ferme-1 & -0.165 & -0.229 & -1.949 & -0.010 & 301 \\
Pradel 2 & Mirabel-Pradel-Ferme-1 & -0.785 & -0.548 & -12.484 & -0.007 & 327 \\
\hline
\end{tabular}

a retaining wall, which may have introduced turbulence and affected the Parsivel measurements.

For the combined SOPs data set, the Parsivel performance statistics before any correction are shown in Table A3, after both velocity and concentration corrections in Table A4, and the changes made to the performance by the DSD correction are shown in Table 7. Again, all data sets were screened for implausible particles. From these data we can see that RMSE, bias, and relative bias were all improved at six of the eight stations. At the other two stations (Lavilledieu and Mirabel) there was a degradation of performance in terms of rain rate, by about $5 \%$ in terms of relative bias. The rela- tive bias at Lavilledieu after the correction was applied was $-6 \%$, which is within the instrumental error limits. Mirabel may have suffered from turbulence effects; its relative bias across the combined SOPs was already $-15 \%$ before any correction was performed. Despite degradations in $R$ bias that were limited to two disdrometers, this analysis of the influence of the correction on the combined SOPs data set confirms its overall benefit to the DSD recorded by Parsivel disdrometers, even at high temporal resolution. 
Table 6. Performance effects of the proposed correction on Parsivel data, and stations on which comparisons were performed, for SOP2013 only at $5 \mathrm{~min}$ time resolution. $N$ is the number of time steps on which comparison was possible (high quality, liquid precipitation only). $\Delta$ RMSE and $\Delta \mid$ bias $\mid$ are in units of millimetres per hour, while $\Delta \mid$ r.bias $\mid$ is a percentage.

\begin{tabular}{llrrrrr}
\hline Parsivel & Pluvio & $\Delta$ RMSE & $\Delta \mid$ bias $\mid$ & $\Delta \mid$ r.bias $\mid$ & $\Delta r^{2}$ & $N$ \\
\hline Mirabel & Mirabel-Mairie & 1.953 & 1.365 & 8.332 & -0.000 & 133 \\
Lussas & Lussas-Salle-Polyvalente & -0.874 & -0.710 & -11.928 & -0.006 & 375 \\
St-Germain & Saint-Germain-Ecole & 0.554 & 0.091 & -4.466 & -0.017 & 204 \\
Lavilledieu & Lavilledieu-Ecole-2 & -0.597 & -0.645 & -14.260 & -0.006 & 387 \\
Pradel Grainage & Pradel Grainage & -0.943 & -0.773 & -15.389 & -0.009 & 377 \\
Les Blaches & Mirabel-Les-Blaches & -0.350 & -0.245 & -3.536 & -0.006 & 194 \\
Pradel 1 & Mirabel-Pradel-Ferme-1 & -0.899 & -0.722 & -16.377 & -0.004 & 218 \\
Pradel 2 & Mirabel-Pradel-Ferme-1 & -0.946 & -0.707 & -16.812 & -0.004 & 167 \\
\hline
\end{tabular}

Table 7. Performance effects of the proposed correction on Parsivel data, and stations on which comparisons were performed, for combined SOPs at $5 \mathrm{~min}$ time resolution. $N$ is the number of time steps on which comparison was possible. $\Delta$ RMSE and $\Delta \mid$ bias $\mid$ are in units of millimetres per hour, while $\Delta \mid$ r.bias $\mid$ is a percentage.

\begin{tabular}{llrrrrr}
\hline Parsivel station & Rain gauge & $\Delta$ RMSE & $\Delta \mid$ bias $\mid$ & $\Delta \mid$ r.bias $\mid$ & $\Delta r^{2}$ & $N$ \\
\hline Mirabel & Mirabel-Mairie & 1.192 & 0.813 & 4.902 & 0.002 & 404 \\
Lussas & Lussas-Salle-Polyvalente & -0.408 & -0.408 & -11.340 & -0.006 & 666 \\
St-Germain & Saint-Germain-Ecole & 0.053 & -0.173 & -7.387 & -0.025 & 859 \\
Lavilledieu & Lavilledieu-Ecole-2 & -0.135 & 0.192 & 2.351 & -0.002 & 1028 \\
Pradel Grainage & Pradel Grainage & -0.943 & -0.773 & -15.389 & -0.018 & 377 \\
Les Blaches & Mirabel-Les-Blaches & -0.269 & -0.404 & -10.363 & -0.012 & 493 \\
Pradel 1 & Mirabel-Pradel-Ferme-1 & -0.478 & -0.618 & -12.473 & -0.018 & 519 \\
Pradel 2 & Mirabel-Pradel-Ferme-1 & -0.838 & -0.603 & -13.473 & -0.012 & 494 \\
\hline
\end{tabular}

\subsection{Results at lower temporal resolution}

To further test the effects of the correction on Parsivel DSDderived rain rates compared to collocated rain gauges, and to test the applicability of the filter to different time resolutions, we performed the same analysis as in the previous section but for $1 \mathrm{~h}$ temporal resolution on the combined SOPs data set. The differences made by the correction to the DSD moments at $1 \mathrm{~h}$ time resolution are shown in Table 8 . At $1 \mathrm{~h}$ time resolution, the correction improved the bias and relative bias on all moment orders, while RMSE was improved for all orders except the third, for which it was hardly changed. $r^{2}$ between moment orders before and after the correction was improved for moments of order $1-3$, and maintained at the same level for the other moments. The differences made to the rain rate to gauge comparisons at $1 \mathrm{~h}$ resolution are shown in Table 9. RMSE was improved at five of the eight stations, and bias at three of the eight. Relative bias was degraded in all but two cases. This degradation is attributable to very small rain rates; indeed, when we selected time steps for which the rain rate was greater than $1.2 \mathrm{~mm} \mathrm{~h}^{-1}$, the relative bias was improved at five of the eight stations, and only the station at Mirabel had an after-correction relative bias that was greater than the instrumental variability. For rain rates between 0.1 and $1.2 \mathrm{~mm} \mathrm{~h}^{-1}$, the after-correction bias was negative at all stations and the per-station mean bias was $-0.12 \mathrm{~mm} \mathrm{~h}^{-1}$. This bias is similar to the bias of the 2DVD compared to the gauge for the same rain rates $\left(-0.08 \mathrm{~mm} \mathrm{~h}^{-1}\right)$. We conclude that our correction procedures result in Parsivel measurements that better match those of the 2DVD, which itself underestimated rain rate for low rain rates when compared to a collocated gauge. We recommend that care is taken with the application of this correction to rain rates below $1.2 \mathrm{~mm} \mathrm{~h}^{-1}$.

\section{Application to Parsivel ${ }^{2}$}

We applied our method to second-generation Parsivels $\left(\right.$ Parsivel $\left.^{2}\right)$ that were also deployed in the HyMeX 2013 campaign. To train the correction for Parsivel ${ }^{2}$ we followed the same method of comparing Parsivel records for the station at Pradel Grainage to the collocated 2DVD to train the correction factors per Parsivel-derived rain intensity class. The only difference was that, due to changes between the first- and second-generation Parsivels, the curves of $P(i)$ per Parsivel-derived intensity class showed different and more complex behaviour to those of the first-generation Parsivel. The classes we used were $[0,0.1),[0.1,0.25),[0.25,0.5)$, $[0.5,1),[1,2)$ and $[2,200) \mathrm{mm} \mathrm{h}^{-1}$.

Apart from the different Parsivel-derived rain intensity class definitions, the training process was identical to that 
Table 8. Time series statistics per moment, comparing Parsivel data (at Pradel Grainage) before (bef.) and after (aft.) the correction is applied to the 2DVD, at $1 \mathrm{~h}$ resolution, for event times in SOP2013. The 2DVD is taken as the reference. Units of bias and RMSE are $\mathrm{m}^{-3} \mathrm{~mm}^{p}$ where $p$ is the moment order. R.b. stands for relative bias.

\begin{tabular}{rrrrrrrrr}
\hline Moment & Bias bef. & Bias aft. & R.b. bef. & R.b. aft. & RMSE bef. & RMSE aft. & $r^{2}$ bef. & $r^{2}$ aft. \\
\hline 0 & 70.73 & -0.29 & 107.59 & -2.07 & 132.63 & 44.10 & 0.45 & 0.76 \\
1 & 30.41 & 0.56 & 60.87 & 0.44 & 65.45 & 38.02 & 0.66 & 0.81 \\
2 & 16.30 & -0.23 & 42.24 & 1.10 & 51.92 & 46.51 & 0.82 & 0.83 \\
3 & 16.07 & -3.29 & 38.72 & 7.10 & 80.21 & 80.20 & 0.84 & 0.82 \\
4 & 35.78 & -12.85 & 46.74 & 10.10 & 201.90 & 190.73 & 0.80 & 0.78 \\
5 & 120.92 & -41.83 & 63.10 & 18.83 & 662.64 & 582.25 & 0.72 & 0.71 \\
6 & 481.63 & -119.21 & 82.49 & 22.79 & 2526.18 & 2107.27 & 0.61 & 0.62 \\
7 & 2127.64 & -232.92 & 102.07 & 40.65 & 10688.27 & 8598.09 & 0.50 & 0.52 \\
\hline
\end{tabular}

Table 9. Performance effects of the proposed correction on Parsivel data, and stations on which comparisons were performed, at $1 \mathrm{~h}$ time resolution, for the combined SOPs. $N$ is the number of time steps on which comparison was possible. $\Delta$ RMSE and $\Delta \mid$ bias $\mid$ are in units of millimetres per hour, while $\Delta \mid$ r.bias $\mid$ is a percentage.

\begin{tabular}{llrrrrr}
\hline Parsivel station & Rain gauge & $\Delta$ RMSE & $\Delta \mid$ bias $\mid$ & $\Delta \mid$ r.bias $\mid$ & $\Delta r^{2}$ & $\mathrm{~N}$ \\
\hline Mirabel & Mirabel-Mairie & 0.486 & 0.332 & 16.265 & 0.004 & 122 \\
Lussas & Lussas-Salle-Polyvalente & -0.088 & 0.136 & 14.326 & 0.006 & 183 \\
St-Germain & Saint-Germain-Ecole & 0.018 & 0.059 & 14.730 & -0.011 & 223 \\
Lavilledieu & Lavilledieu-Ecole-2 & 0.146 & 0.292 & 23.862 & -0.005 & 277 \\
Pradel Grainage & Pradel Grainage & -0.108 & -0.096 & -14.164 & -0.020 & 131 \\
Les Blaches & Mirabel-Les-Blaches & -0.089 & 0.031 & 12.701 & -0.006 & 117 \\
Pradel 1 & Mirabel-Pradel-Ferme-1 & -0.141 & -0.034 & 12.195 & -0.011 & 130 \\
Pradel 2 & Mirabel-Pradel-Ferme-1 & -0.220 & -0.156 & -4.583 & -0.014 & 118 \\
\hline
\end{tabular}

shown in Sect. 5. The resulting correction factors are shown for the HyMeX Parsivel ${ }^{2}$ data set in Table 10. A comparison of the corrections for first- and second-generation Parsivel is shown in Fig. 15 and shows significant differences. Differences are expected, given that at a minimum the laser is different between the two instruments. Both filters were similar for drops up to about $1 \mathrm{~mm}$ in diameter, in that they both show the Parsivel overestimating drops in comparison to the 2DVD. Parsivel ${ }^{2}$ is shown to underestimate the numbers of drops between 1.38 and $3.25 \mathrm{~mm}$ diameter. Drops larger than $3.5 \mathrm{~mm}$ were overestimated by both generations of Parsivel, but less so by Parsivel ${ }^{2}$.

After training the correction factors we applied them to Parsivel $^{2}$ data for all available stations. Due to small differences in clock times between the rain gauges and Parsivel ${ }^{2}$ stations we used $1 \mathrm{~h}$ time resolution. We first compared the moments to the 2DVD moments for event time steps only; these results are shown in Table 12. The bias was improved for moments of order $0-3,6$, and 7, but was degraded for moments of order 4 and 5 . Moments of orders 4 and 5 had the two lowest biases before the correction. In contrast, the relative bias was improved for all moment orders except the sixth, where it was maintained essentially at the same level, and the seventh. This indicates that the distribution of differences for moment of orders 4 and 5 may have included out- liers which affected the bias. RMSE and $r^{2}$ were improved for all moment orders.

We compared the rain rates after the correction of Parsivel ${ }^{2}$ to those recorded by collocated rain gauges, for all available time steps. Due to timing errors with the Parsivel ${ }^{2}$ network, we applied the correction to $1 \mathrm{~h}$ time steps. The results are shown in Table 11. Absolute and relative bias were improved at one station, but degraded at the others. Again, there appears to be an effect of low rain rate on these performance statistics. When we counted only time steps with rain rates at or above $1.2 \mathrm{~mm} \mathrm{~h}^{-1}$, the worst degradation in relative bias dropped from 20 to $14 \%$. There were many outliers in these data sets, and work is ongoing to further refine the correction on these Parsivel ${ }^{2}$ data. Despite this degradation, the correction improved the DSD moments compared to the 2DVD. We hypothesise that training the Parsivel ${ }^{2}$ correction factors using more data and therefore a lower time resolution, plus fixing potential clock issues in this data set, would improve the performance of the correction on Parsivel $^{2}$ data.

\section{Application to another climatology}

Finally, we applied our technique to data collected in a different region and climatology (see Sect. 3.2). In the Payerne 2014 campaign, a 2DVD and first-generation Parsivel 
Table 10. Calibrated Parsivel ${ }^{2}$ correction factors for Parsivel-derived intensity classes for the HyMeX 2013 campaigns. Each row contains the class number, the centre equivolume diameter for the class $\left(D_{i}\right)$, and the calibrated factors $\mathrm{P}(\mathrm{i})$ for each class of Parsivel-derived intensity. Intensity class boundaries are provided in millimetres per hour.

\begin{tabular}{|c|c|c|c|c|c|c|c|}
\hline Class $(i)$ & $D_{i}(\mathrm{~mm})$ & {$[0,0.1)$} & {$[0.1,0.25)$} & {$[0.25,0.5)$} & {$[0.5,1)$} & {$[1,2)$} & {$[2,200)$} \\
\hline 3 & 0.31 & 0.02 & 0.04 & 0.04 & 0.05 & 0.06 & 0.07 \\
\hline 4 & 0.44 & 0.03 & 0.05 & 0.05 & 0.07 & 0.11 & 0.16 \\
\hline 5 & 0.56 & 0.11 & 0.16 & 0.19 & 0.22 & 0.30 & 0.36 \\
\hline 6 & 0.69 & 0.20 & 0.26 & 0.29 & 0.36 & 0.45 & 0.54 \\
\hline 7 & 0.81 & 0.36 & 0.47 & 0.52 & 0.53 & 0.71 & 0.78 \\
\hline 8 & 0.94 & 0.55 & 0.55 & 0.67 & 0.67 & 0.80 & 0.86 \\
\hline 9 & 1.06 & 0.86 & 0.85 & 0.94 & 0.89 & 1.01 & 1.03 \\
\hline 10 & 1.19 & 0.74 & 0.84 & 1.08 & 0.90 & 1.17 & 1.03 \\
\hline 11 & 1.38 & 1.04 & 1.13 & 1.22 & 1.12 & 1.36 & 1.12 \\
\hline 12 & 1.62 & 1.10 & 1.20 & 1.35 & 1.19 & 1.37 & 1.10 \\
\hline 13 & 1.88 & 1.14 & 0.97 & 1.34 & 1.17 & 1.41 & 1.04 \\
\hline 14 & 2.12 & & & 1.25 & 1.17 & 1.22 & 0.97 \\
\hline 15 & 2.38 & & & 1.29 & 1.17 & 1.43 & 1.06 \\
\hline 16 & 2.75 & & & 1.43 & & 1.37 & 1.07 \\
\hline 17 & 3.25 & & & 0.51 & & 1.31 & 1.02 \\
\hline 18 & 3.75 & & & & & & 0.97 \\
\hline 19 & 4.25 & & & & & & 0.73 \\
\hline 20 & 4.75 & & & & & & 0.58 \\
\hline 21 & 5.50 & & & & & & 0.45 \\
\hline 22 & 6.50 & & & & & & 0.32 \\
\hline
\end{tabular}

Table 11. Performance effects of the proposed correction on Parsivel ${ }^{2}$ network data, and stations on which comparisons were performed. $N$ is the number of time steps on which comparison was possible. $\Delta$ RMSE and $\Delta \mid$ bias $\mid$ are in units of millimetres per hour, while $\Delta \mid$ r.bias $\mid$ is a percentage.

\begin{tabular}{llrrrrr}
\hline Parsivel & Pluvio & $\Delta$ RMSE & $\Delta \mid$ bias $\mid$ & $\Delta \mid$ r.bias $\mid$ & $\Delta r^{2}$ & $N[\mathrm{~h}]$ \\
\hline Villeneuve-de-Berg & Villeneuve-de-Berg-2 & 0.05 & 0.11 & 7.34 & -0.01 & 129 \\
Mont-Redon & Mirabel-Mont-Redon & 0.03 & -0.08 & -19.68 & -0.00 & 128 \\
Pradel-Vignes & Mirabel-Pradel-Vignes & 0.07 & 0.17 & 0.94 & 0.00 & 58 \\
Pradel Grainage & Pradel Grainage & 0.29 & 0.34 & 9.65 & -0.01 & 154 \\
Villeneuve-de-Berg 2 & Villeneuve-de-Berg-2 & 0.17 & 0.33 & 17.49 & -0.01 & 132 \\
\hline
\end{tabular}

were collocated. When compared to a collocated rain gauge at $1 \mathrm{~h}$ resolution, the 2DVD recorded rain rates with a performance very similar to that shown in the SOP2013 campaign (see Sect. 4.4), with a mean ratio of 0.84 , an RMSE of $0.24 \mathrm{~mm} \mathrm{~h}^{-1}$, an $r^{2}$ of 0.98 , bias of $-0.15 \mathrm{~mm} \mathrm{~h}^{-1}$, and a relative bias of $-19 \%$.

We used the same technique as described in Sect. 5, using data with $1 \mathrm{~h}$ temporal resolution for training, and $10 \mathrm{~min}$ resolution (the resolution of the reference rain gauge) for testing. We used the same Parsivel-derived intensity classes as for SOP2013. The resulting correction factors are shown in Table 13. The correction is compared to the correction found in SOP2013, per Parsivel-derived rain rate class, in Fig. 16. These plots show that the trained correction factors were very similar across climatologies, for classes of low rain rates $\left(0-1 \mathrm{~mm} \mathrm{~h}^{-1}\right)$. For larger rain rates, there were some differences between the correction factors, but the general shape remained the same. It should be noted that in the Payerne 2014 data set, the precipitation sampled had much lower intensity than that found in SOP2013, and we hypothesise that the differences are due to these sampling effects. We tested the results using both $1 \mathrm{~h}$ and $10 \mathrm{~min}$ resolution data sets.

For consistency, we kept the threshold for the maximumallowed spread in $P(i)$ at 0.7. In the Payerne 2014 data set, there appears to be greater sensitivity to this threshold, indicating that the sample size available for training was smaller than in SOP2013. For this reason we also tested the results when the correction trained using SOP2013 was applied to the Payerne 2014 data set. The effect on Parsivel rain rate performances are summarised in Table 14. The comparisons of moments with those of the 2DVD are included in the appendix, in Tables A5, A6, and A7.

The results show that when the Payerne data set was used to train the correction factors, there was a slight improvement 
Table 12. Time series statistics per moment, comparing Parsivel ${ }^{2}$ data (at Pradel Grainage) before (bef.) and after (aft.) the correction is applied, to the 2DVD, at $1 \mathrm{~h}$ resolution, for event times. The 2DVD is taken as the reference. Units of bias and RMSE are per cubic metres per millimetre $\left(p \mathrm{~m}^{-3} \mathrm{~mm}^{p}\right)$ where $p$ is the moment order. R.b stands for relative bias.

\begin{tabular}{rrrrrrrrr}
\hline Moment & Bias bef. & Bias aft. & R.b. bef. & R.b. aft. & RMSE bef. & RMSE aft. & $r^{2}$ bef. & $r^{2}$ aft. \\
\hline 0 & 166.10 & -3.20 & 268.90 & -0.46 & 252.12 & 44.46 & 0.39 & 0.78 \\
1 & 74.22 & -1.25 & 172.75 & 0.65 & 113.59 & 38.17 & 0.55 & 0.82 \\
2 & 34.10 & -1.51 & 90.83 & 0.78 & 65.85 & 45.19 & 0.77 & 0.85 \\
3 & 13.52 & -3.78 & 49.64 & 0.12 & 73.42 & 70.83 & 0.87 & 0.88 \\
4 & 1.56 & -11.12 & 29.01 & -0.18 & 144.25 & 144.89 & 0.89 & 0.90 \\
5 & 9.54 & -35.47 & 14.18 & -3.64 & 399.39 & 381.95 & 0.89 & 0.91 \\
6 & 150.37 & -123.07 & 4.64 & -4.66 & 1553.18 & 1261.94 & 0.88 & 0.92 \\
7 & 1141.04 & -462.26 & -2.21 & -7.28 & 7617.83 & 4977.42 & 0.87 & 0.91 \\
\hline
\end{tabular}

Table 13. Calibrated Parsivel correction factors for Parsivel-derived intensity classes for the Payerne 2014 campaign. Each row contains the class number, the centre equivolume diameter for the class $\left(D_{i}\right)$, and the calibrated factors $P(i)$ for each class of Parsivel-derived intensity. Intensity class boundaries are provided in millimetres per hour.

\begin{tabular}{lrrrrr}
\hline Class $(i)$ & $D_{i}(\mathrm{~mm})$ & {$[0,0.5)$} & {$[0.5,1)$} & {$[1,2)$} & {$[2,200)$} \\
\hline 3 & 0.31 & 0.04 & 0.04 & 0.10 & 0.08 \\
4 & 0.44 & 0.08 & 0.13 & 0.22 & 0.21 \\
5 & 0.56 & 0.28 & 0.37 & 0.44 & 0.50 \\
6 & 0.69 & 0.40 & 0.44 & 0.51 & 0.65 \\
7 & 0.81 & 0.58 & 0.61 & 0.70 & 0.86 \\
8 & 0.94 & 0.61 & 0.65 & 0.66 & 0.82 \\
9 & 1.06 & 0.78 & 0.77 & 0.74 & 0.94 \\
10 & 1.19 & 0.68 & 0.75 & 0.71 & 0.96 \\
11 & 1.38 & 0.72 & 0.73 & 0.70 & 0.93 \\
12 & 1.62 & 0.70 & 0.62 & 0.68 & 0.98 \\
13 & 1.88 & 0.69 & 0.50 & 0.54 & 0.96 \\
14 & 2.12 & 0.50 & 0.49 & 0.55 & 0.88 \\
15 & 2.38 & 0.59 & 0.52 & 0.34 & 0.74 \\
16 & 2.75 & 0.40 & 0.58 & 0.47 & 0.62 \\
17 & 3.25 & 0.50 & 0.61 & 0.27 & 0.68 \\
18 & 3.75 & & 0.66 & 0.53 & 0.52 \\
19 & 4.25 & & 0.32 & & 0.51 \\
20 & 4.75 & & & & 0.19 \\
21 & 5.50 & & & & 0.46 \\
\hline
\end{tabular}

in the Parsivel's rain rate estimation at 10 min resolution. At $1 \mathrm{~h}$ resolution, the absolute bias was maintained but the relative bias was degraded. Correlations were maintained by the correction. When the HyMeX-trained correction was applied to the Payerne data set, the performance was improved again. This indicates again that the sample size of the Payerne data set may have been smaller than required for a representative set of correction factors to be trained. Whether the Payernetrained or HyMeX-trained correction factors were used, there was an improvement in the match between Parsivel and the 2DVD at Payerne for all moments. This suggests that the cor-
Table 14. Summary of performance effects of the Parsivel correction, for Payerne 2014. Set indicates which data set was used to train the correction factors using one resolution (Pay - Payerne 2014, S13 - SOP2013), Res. is the temporal resolution to which the corrections were applied, and $N$ is the number of time steps to which the correction was applied. $\Delta$ RMSE and $\Delta \mid$ bias $\mid$ are in units of millimetres per hour, while $\Delta \mid$ r.b. $\mid$ (relative bias) is a percentage.

\begin{tabular}{llrrrrr}
\hline Set & Res. & $\Delta$ RMSE & $\Delta \mid$ bias $\mid$ & $\Delta \mid$ r.b. $\mid$ & $\Delta r^{2}$ & $N$ \\
\hline Pay & $10 \mathrm{~m}$ & -0.108 & -0.048 & -4.937 & -0.002 & 435 \\
Pay & $1 \mathrm{~h}$ & -0.015 & -0.003 & 3.879 & -0.004 & 164 \\
S13 & $10 \mathrm{~m}$ & -0.131 & -0.131 & -9.570 & -0.003 & 435 \\
\hline
\end{tabular}

rection is robust and can be applied as such in different climatic regions.

\section{Conclusions}

We have developed a method to correct raindrop size distributions recorded by Parsivel disdrometers, using a twodimensional video disdrometer as a reference instrument. The correction is made in two steps. First, raw Parsivel drop counts binned by velocity and diameter are shifted so that per-diameter-class mean velocities align with expected terminal velocities. The raw data can then be screened for particles that are unlikely to be raindrops, and per-diameter-class volumetric drop concentrations can then be calculated. Second, these volumetric drop concentrations are adjusted by factors trained by reference to the 2DVD. The adjustment causes the drop concentrations to match those of the 2DVD in a statistical way.

The correction was applied to Parsivel and Parsivel ${ }^{2}$ data from two autumn field campaigns in Ardèche, France. The results showed an improvement in the accuracy of moments of the DSD, when compared to the 2DVD as the reference instrument. Comparison of rain rate with collocated rain gauges showed changes that are acceptable, given the overall improvement in the accuracy of the DSD afforded by the 


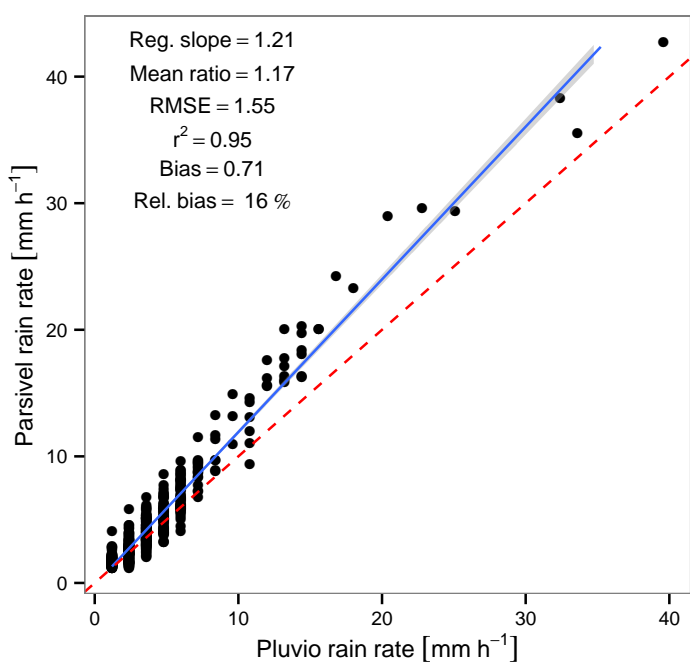

(a) Physical drops only.

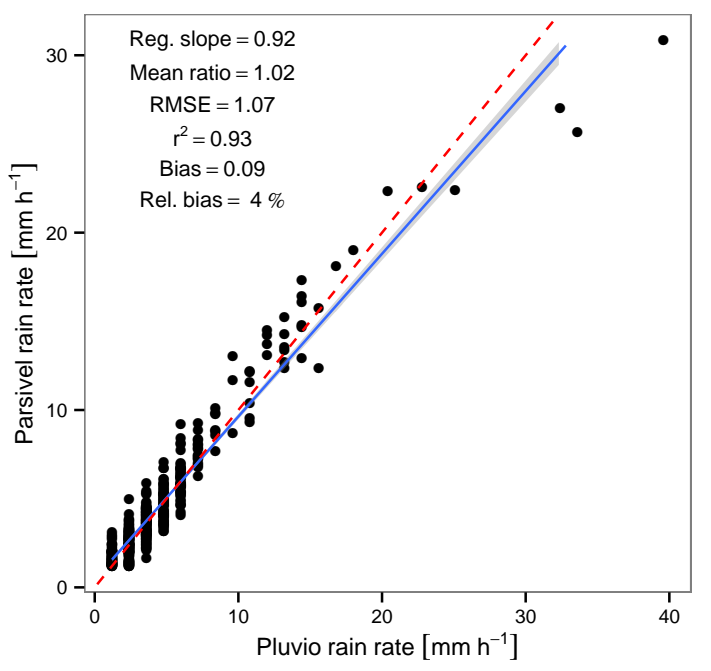

(b) Concentrations corrected.

Figure 14. Scatterplots showing the effect of the proposed correction, for the combined SOPs, with liquid precipitation only and rain rates over $1.2 \mathrm{~mm} \mathrm{~h}^{-1}$, for Pradel 1, the closest station to the 2DVD that was present in both 2012 and 2013.

correction. It must be noted that because the 2DVD is used as the reference instrument, the adjusted Parsivel drop size distributions will be, at best, as accurate as the measurements obtained by the 2DVD. If a better reference becomes available, exactly the same approach could be applied to correct the Parsivel (or indeed any other disdrometer) and to improve the agreement with the reference.

The correction was shown to be timescale-independent through application to both $5 \mathrm{~min}$ and $1 \mathrm{~h}$ Parsivel records. While in this case the correction was trained on data sets containing mainly light to intermediate rain rates (mostly below $20 \mathrm{~mm} \mathrm{~h}^{-1}$ ), the method is flexible because it is conditioned on the Parsivel-derived rain intensity, and could be trained for higher rain rate classes as required. The method does not

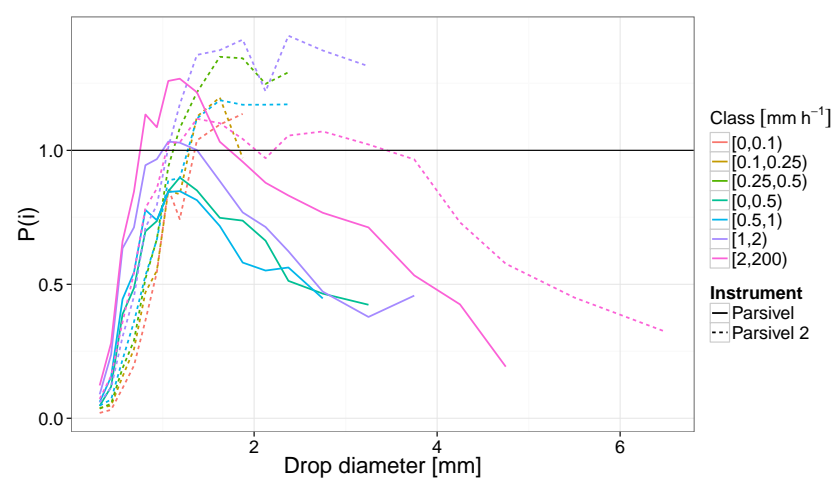

Figure 15. Comparison between correction factors for different generations of Parsivel disdrometers in SOP2013.
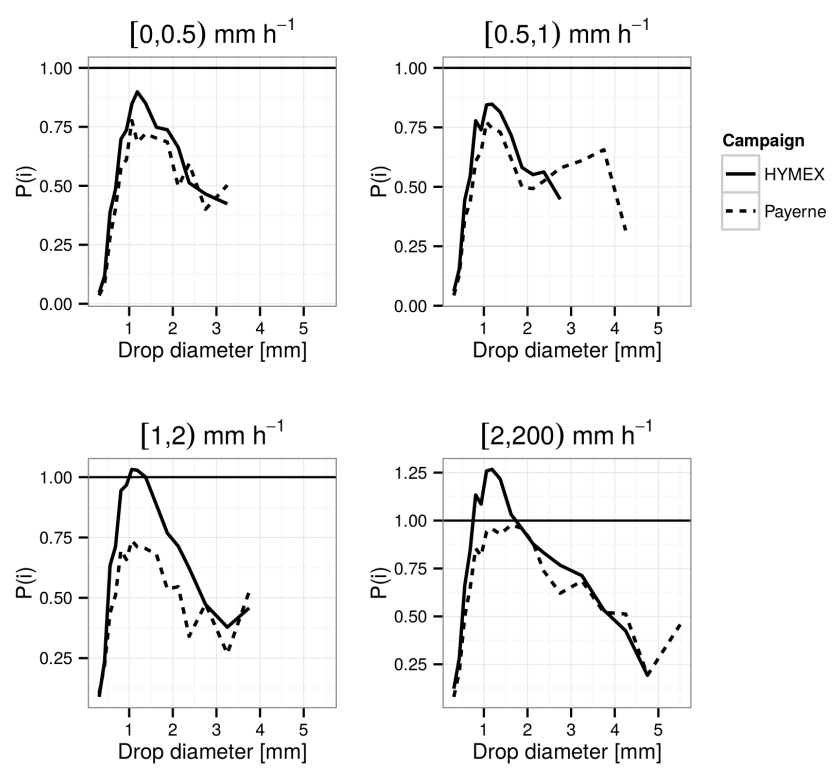

Figure 16. Comparison between correction factors for different campaigns, Payerne 2014 and SOP2013. Both sets were trained on data at $1 \mathrm{~h}$ time resolution.

involve changing the hardware or software of the instrument, and it can be applied retrospectively to existing data sets. The correction offers the ability to improve the accuracy of the DSDs recorded by Parsivel disdrometers, which are instruments that are especially suitable for deployment in networks. High-quality DSD measurements from networks of Parsivel disdrometers can be used in valuable work on topics such as the small-scale variability of the drop size distribution. The correction has been demonstrated to work across two different climatologies in Europe, and work is ongoing to further test the transferability of the method. 


\section{Appendix A: Extra data tables}

Table A1. Clock adjustments (A) for 2DVD events in HyMeX SOP2013.

\begin{tabular}{lllr}
\hline Event & From (UTC) & To (UTC) & A (s) \\
\hline 24,25 & $20-10-2013,00: 00: 00$ & $24-10-2013,00: 00: 00$ & 60 \\
26 & $27-10-2013,00: 00: 00$ & $28-10-2013,00: 00: 00$ & 30 \\
27 & $02-11-2013,00: 00: 00$ & $03-11-2013,00: 00: 00$ & 60 \\
28 & $04-11-2013,00: 00: 00$ & $05-11-2013,00: 00: 00$ & 60 \\
29 & $05-11-2013,00: 00: 00$ & $06-11-2013,00: 00: 00$ & 30 \\
30 & $18-11-2013,00: 00: 00$ & $19-11-2013,00: 00: 00$ & 30 \\
\hline
\end{tabular}

Table A2. Numbers of large drops recorded by the 2DVD during the combined SOP event times.

\begin{tabular}{lrr}
\hline $\begin{array}{l}\text { Diameter } \\
\text { class (mm) }\end{array}$ & $\begin{array}{r}\text { Number of } \\
\text { drops }\end{array}$ & $\begin{array}{r}\% \text { total } \\
\text { drops }\end{array}$ \\
\hline$(5,5.5]$ & 273 & 0.00531 \\
$(5.5,6]$ & 97 & 0.00189 \\
$(6,6.5]$ & 36 & 0.00070 \\
$(6.5,7]$ & 10 & 0.00019 \\
$(7,7.5]$ & 3 & 0.00006 \\
$(7.5,8]$ & 1 & 0.00002 \\
\hline
\end{tabular}

Table A3. Performance statistics for rain rate per Parsivel station for the combined SOPs at $5 \mathrm{~min}$ resolution, before the DSD correction is applied. RMSE (E) and bias are in units of millimetres per hour; relative bias (R.b.) is a percentage. F stands for fit slope, $M$ stands for mean ratio, and Pradel Grain. stands for Pradel Grainage.

\begin{tabular}{lrrrrrr}
\hline Station & E & Bias & $r^{2}$ & R.b. & F & M \\
\hline Mirabel & 1.49 & -0.65 & 0.98 & -15.18 & 1.03 & 0.90 \\
Lussas & 1.55 & 0.51 & 0.94 & 11.99 & 1.18 & 1.12 \\
St-Germain & 1.06 & 0.35 & 0.96 & 7.83 & 1.12 & 1.08 \\
Lavilledieu & 1.24 & 0.22 & 0.96 & 3.75 & 1.14 & 1.05 \\
Pradel Grain. & 2.04 & 1.12 & 0.97 & 26.22 & 1.29 & 1.28 \\
Les Blaches & 1.35 & 0.50 & 0.95 & 10.46 & 1.17 & 1.13 \\
Pradel 1 & 1.55 & 0.71 & 0.95 & 16.12 & 1.21 & 1.17 \\
Pradel 2 & 1.69 & 0.88 & 0.97 & 20.40 & 1.29 & 1.22 \\
\hline
\end{tabular}

Table A4. Performance statistics for rain rate per Parsivel station for the combined SOPs at 5 min resolution, after the DSD correction is applied. RMSE (E) and bias are in units of $\mathrm{mm} \mathrm{h}^{-1}$; relative bias (R.b.) is a percentage. F stands for fit slope, $\mathrm{M}$ stands for mean ratio, and Pradel Grain. stands for Pradel Grainage.

\begin{tabular}{lrrrrrr}
\hline Station & $\mathrm{E}$ & $\mathrm{Bias}$ & $r^{2}$ & R.b. & $\mathrm{F}$ & $\mathrm{M}$ \\
\hline Mirabel & 2.69 & -1.46 & 0.98 & -20.08 & 0.76 & 0.79 \\
Lussas & 1.14 & -0.10 & 0.94 & 0.65 & 0.90 & 0.98 \\
St-Germain & 1.11 & -0.18 & 0.94 & -0.45 & 0.85 & 0.96 \\
Lavilledieu & 1.11 & -0.41 & 0.96 & -6.11 & 0.88 & 0.92 \\
Pradel Grain. & 1.09 & 0.35 & 0.96 & 10.83 & 0.94 & 1.08 \\
Les Blaches & 1.08 & -0.10 & 0.94 & -0.10 & 0.87 & 0.98 \\
Pradel 1 & 1.07 & 0.09 & 0.93 & 3.64 & 0.92 & 1.02 \\
Pradel 2 & 0.85 & 0.27 & 0.96 & 6.93 & 0.97 & 1.06 \\
\hline
\end{tabular}


Table A5. Time series statistics per moment, comparing Parsivel data for Payerne 2014 before (bef.) and after (aft.) the correction is applied, to the 2DVD, at $10 \mathrm{~min}$ resolution. The 2DVD is taken as the reference. Units of bias and RMSE are per cubic metre per millimetre $p$ $\left(\mathrm{m}^{-3} \mathrm{~mm}^{p}\right)$ where $p$ is the moment order. R.b stands for relative bias.

\begin{tabular}{rrrrrrrrr}
\hline Moment & Bias bef. & Bias aft. & R.b. bef. & R.b. aft. & RMSE bef. & RMSE aft. & $r^{2}$ bef. & $r^{2}$ aft. \\
\hline 0 & 133.26 & 2.01 & 231.25 & 3.60 & 196.68 & 24.64 & 0.67 & 0.94 \\
1 & 64.71 & 2.02 & 154.15 & 4.73 & 94.61 & 17.40 & 0.79 & 0.96 \\
2 & 38.07 & 1.87 & 109.95 & 6.75 & 55.90 & 16.22 & 0.90 & 0.97 \\
3 & 29.06 & 1.71 & 88.31 & 8.39 & 44.92 & 20.72 & 0.95 & 0.97 \\
4 & 31.66 & 1.53 & 78.41 & 12.34 & 60.23 & 37.56 & 0.97 & 0.96 \\
5 & 53.86 & 2.16 & 80.14 & 17.03 & 153.13 & 98.52 & 0.97 & 0.94 \\
6 & 141.20 & 11.87 & 87.77 & 22.58 & 567.75 & 356.38 & 0.95 & 0.89 \\
7 & 505.55 & 91.94 & 102.59 & 31.68 & 2536.41 & 1660.16 & 0.90 & 0.77 \\
\hline
\end{tabular}

Table A6. Time series statistics per moment, comparing Parsivel data for Payerne 2014 before (bef.) and after (aft.) the correction is applied, to the 2DVD, at $1 \mathrm{~h}$ resolution. The 2DVD is taken as the reference. Units of bias and RMSE are per cubic metre per millimetre $p\left(\mathrm{~m}^{-3} \mathrm{~mm}^{p}\right)$ where $p$ is the moment order. R.b stands for relative bias.

\begin{tabular}{rrrrrrrrr}
\hline Moment & Bias bef. & Bias aft. & R.b. bef. & R.b. aft. & RMSE bef. & RMSE aft. & $r^{2}$ bef. & $r^{2}$ aft. \\
\hline 0 & 81.23 & 0.65 & 266.11 & 0.92 & 129.14 & 11.97 & 0.77 & 0.96 \\
1 & 39.42 & 0.69 & 172.77 & 3.22 & 63.03 & 8.62 & 0.85 & 0.97 \\
2 & 23.08 & 0.56 & 120.47 & 1.65 & 37.52 & 7.72 & 0.91 & 0.98 \\
3 & 17.26 & 0.37 & 80.41 & 3.04 & 29.04 & 8.99 & 0.95 & 0.98 \\
4 & 17.74 & 0.18 & 66.01 & 3.28 & 32.94 & 14.15 & 0.98 & 0.98 \\
5 & 27.28 & 0.73 & 69.61 & 7.50 & 66.29 & 30.07 & 0.99 & 0.98 \\
6 & 64.91 & 8.04 & 74.55 & 12.27 & 216.27 & 92.68 & 0.99 & 0.96 \\
7 & 221.52 & 62.86 & 85.83 & 20.23 & 898.23 & 439.25 & 0.97 & 0.89 \\
\hline
\end{tabular}

Table A7. Time series statistics per moment, comparing Parsivel data for Payerne 2014 before (bef.) and after (aft.) the correction is applied, to the 2DVD, at $10 \mathrm{~min}$ resolution. In this case the SOP2013 correction is applied to the Payerne 2014 data set. The 2DVD is taken as the reference. Units of bias and RMSE are $\mathrm{m}^{-3} \mathrm{~mm}^{p}$ where $p$ is the moment order. R.b stands for relative bias.

\begin{tabular}{rrrrrrrrr}
\hline Moment & Bias bef. & Bias aft. & R.b. bef. & R.b. aft. & RMSE bef. & RMSE aft. & $r^{2}$ bef. & $r^{2}$ aft. \\
\hline 0 & 133.26 & 22.61 & 231.25 & 31.53 & 196.68 & 43.57 & 0.67 & 0.94 \\
1 & 64.71 & 18.33 & 154.15 & 32.52 & 94.61 & 35.98 & 0.79 & 0.95 \\
2 & 38.07 & 16.34 & 109.95 & 33.84 & 55.90 & 34.20 & 0.90 & 0.96 \\
3 & 29.06 & 16.07 & 88.31 & 34.31 & 44.92 & 37.72 & 0.95 & 0.95 \\
4 & 31.66 & 17.58 & 78.41 & 36.23 & 60.23 & 51.95 & 0.97 & 0.95 \\
5 & 53.86 & 22.61 & 80.14 & 39.17 & 153.13 & 108.50 & 0.97 & 0.93 \\
6 & 141.20 & 41.75 & 87.77 & 45.30 & 567.75 & 366.53 & 0.95 & 0.89 \\
7 & 505.55 & 140.46 & 102.59 & 53.95 & 2536.41 & 1687.96 & 0.90 & 0.77 \\
\hline
\end{tabular}


Acknowledgements. The authors thank the maintainers of the HPicoNet rain gauge and Parsivel ${ }^{2}$ network: Brice Boudevillain, Gilles Molinié, and Simon Gérard from the Laboratoire d'étude des Transferts en Hydrologie et Environnement (LTHE) at Grenoble University. Rain gauge and Parsivel $^{2}$ data were obtained from the HyMeX program, sponsored by grants MISTRALS/HyMeX, ANR-2011-BS56-027 FLOODSCALE project and OHMCV. The authors thank Jacopo Grazioli, Marc Schleiss, Joël Jaffrain, and Daniel Wolfensberger, for their work on the Parsivel and 2DVD network deployed in HyMeX SOPs 2012 and 2013. The authors thank Joël Jaffrain and Meteoswiss for their work on installation and maintenance of instruments in the Payerne 2014 campaign. Finally, the authors acknowledge the financial support of the Swiss National Science Foundation under grant 2000021_140669.

Edited by: G. Vulpiani

\section{References}

Andsager, K., Beard, K. V., and Laird, N. F.: Laboratory measurements of axis ratios for large rain drops, J. Atmos. Sci., 56, 26732683, 1999.

Atlas, D., Srivastava, R., and Sekhon, R. S.: Doppler radar characteristics of precipitation at vertical incidence, Rev. Geophys., 11, 1-35, 1973.

Battaglia, A., Rustemeier, E., Tokay, A., Blahak, U., and Simmer, C.: PARSIVEL snow observations: a critical assessment, J. Atmos. Oceanic Technol., 27, 333-344, doi:10.1175/2009JTECHA1332.1, 2010.

Beard, K. V.: Terminal velocity and shape of cloud and precipitation drops aloft, J. Atmos. Sci., 33, 851-864, 1976.

Beard, K. V. and Chuang, C.: A new model for the equilibrium shape of raindrops, J. Atmos. Sci., 44, 1509-1524, 1987.

Brandes, E., Zhang, G., and Vivekanandan, J.: Experiments in rainfall estimation with a polarimetric radar in a subtropical environment, J. Appl. Meteor., 41, 674-685, 2002.

Drobinski, P., Ducrocq, V., Alpert, P., Anagnostou, E., Béranger, K., Borga, M., Braud, I., Chanzy, A., Davolio, S., Delrieu, G., Estournel, C., Filali Boubrahmi, N., Font, J., Grubisic, V., Gualdi, S., Homar, V., Ivancan-Picek, B., Kottmeier, C., Kotroni, V., Lagouvardos, K., Lionello, P., Llasat, M. C., Ludwig, W., Lutoff, C., Mariotti, A., Richard, E., Romero, R., Rotunno, R., Roussot, O., Ruin, I., Somot, S., Taupier-Letage, I., Tintore, J., Uijlenhoet, R., and Wernli, H.: HyMeX, a 10-year multidisciplinary program on the Mediterranean water cycle, Bull. Amer. Meteor. Soc., 95, 1063-1082, doi:10.1175/BAMS-D-12-00242.1, 2014.

Frei, C. and Schär, C.: A precipitation climatology of the Alps from high-resolution rain-gauge observations, Int. J. Climatol., 18, 873-900, 1998.

Jaffrain, J. and Berne, A.: Experimental quantification of the sampling uncertainty associated with measurements from Parsivel disdrometers, J. Hydrometeor., 12, 352-370, doi:10.1175/2010JHM1244.1, 2011.

Jaffrain, J., Studzinski, A., and Berne, A.: A network of disdrometers to quantify the small-scale variability of the raindrop size distribution, Water Resour. Res., 47, W00H06, doi:10.1029/2010WR009872, 2011.
Jameson, A. R. and Kostinski, A. B.: What is a raindrop size distribution?, Bull. Amer. Meteor. Soc., 82, 1169-1177, 2001.

Krajewski, W. F., Kruger, A., Caracciolo, C., Golé, P., Barthes, L., Creutin, J.-D., Delahaye, J.-Y., Nikolopoulos, E. I., Ogden, F., and Vinson, J.-P.: DEVEX-disdrometer evaluation experiment: basic results and implications for hydrologic studies, Adv. Water Resour., 29, 807-814, doi:10.1016/j.advwatres.2005.03.018, 2006.

Kruger, A. and Krajewski, W. F.: Two-dimensional video disdrometer: a description, J. Atmos. Oceanic Technol., 19, 602-617, 2002.

Löffler-Mang, M. and Joss, J.: An optical disdrometer for measuring size and velocity of hydrometeors, J. Atmos. Oceanic Technol., 17, 130-139, 2000.

MeteoFrance: Données climatiques de la station de Montélimar, http://www.meteofrance.com/climat/france/station/26198001/ normales (last access: 20 November 2014), 2014.

MeteoSwiss: Federal Office of Meteorology and Climatology MeteoSwiss, Climate normals Payerne, Reference period 1981-2010, http://meteosuisse.ch/files/kd/climsheet/en/PAY _ norm8110.pdf (last access: 20 November 2014), 2013.

Nešpor, V., Krajewski, W. F., and Kruger, A.: Wind-induced error of raindrop size distribution measurement using a two-dimensional video disdrometer, J. Atmos. Ocean. Technol., 17, 1483-1492, 2000.

Olsen, R. L., Rogers, D. V., and Hodge, D. B.: The $\mathrm{aR}^{\mathrm{b}}$ relation in the calculation of rain attenuation, IEEE T. Antenn. Propag., 26, 318-329, 1978.

Peel, M. C., Finlayson, B. L., and McMahon, T. A.: Updated world map of the Köppen-Geiger climate classification, Hydrol. Earth Syst. Sci., 11, 1633-1644, doi:10.5194/hess-11-16332007, 2007.

Pruppacher, H. R. and Klett, J. D.: Microphysics of clouds and precipitation, Kluwer Academic Publishers, Dordrecht, 2nd rev. and enl. Edn., with an introduction to cloud chemistry and cloud electricity Edn., 2000.

Ricard, D., Ducrocq, V., and Auger, L.: A climatology of the mesoscale environment associated with heavily precipitating events over a northwestern Mediterranean area, J. Appl. Meteorol. Climatol., 51, 468-488, 2012.

Roe, G. H.: Orographic precipitation, Ann. Rev. Earth Planet Sci., 33, 645-671, 2005.

Schönhuber, M., Lammer, G., and Randeu, W. L.: One decade of imaging precipitation measurement by $2 \mathrm{D}$-video-distrometer, Adv. Geosci., 10, 85-90, doi:10.5194/adgeo-10-85-2007, 2007.

Schönhuber, M., Lammer, G., and Randeu, W. L.: The 2D-videodistrometer, in: Precipitation: Advances in measurement, estimation and prediction, 3-31, Springer, 2008.

Tapiador, F., Checa, R., and De Castro, M.: An experiment to measure the spatial variability of rain drop size distribution using sixteen laser disdrometers, Geophys. Res. Lett., 37, L16803, doi:10.1029/2010GL044120, 2010.

Testud, J., Oury, S., Black, R. A., Amayenc, P., and Dou, X.: The concept of "normalized" distribution to describe raindrop spectra: a tool for cloud physics and cloud remote sensing, J. Appl. Meteor., 40, 1118-1140, 2001.

Thurai, M. and Bringi, V. N.: Drop axis ratios from a 2D video disdrometer, J. Atmos. Oceanic Technol., 22, 966-978, doi:10.1175/JTECH1767.1, 2005. 
Thurai, M., Huang, G., Bringi, V., Randeu, W., and Schönhuber, M.: Drop shapes, model comparisons, and calculations of polarimetric radar parameters in rain, J. Atmos. Ocean. Technol., 24, 1019-1032, 2007.

Thurai, M., Petersen, W. A., Tokay, A., Schultz, C., and Gatlin, P.: Drop size distribution comparisons between Parsivel and 2-D video disdrometers, Adv. Geosci., 30, 3-9, doi:10.5194/adgeo30-3-2011, 2011.

Tokay, A., Kruger, A., and Krajewski, W.: Comparison of drop size distribution measurements by impact and optical disdrometers, $\mathrm{J}$. Appl. Meteor., 40, 2083-2097, 2001.

Tokay, A., Petersen, W. A., Gatlin, P., and Wingo, M.: Comparison of raindrop size distribution measurements by collocated disdrometers, J. Atmos. Ocean. Technol., 30, 1672-1690, doi:10.1175/JTECH-D-12-00163.1, 2013.

Tokay, A., Wolff, D. B., and Petersen, W. A.: Evaluation of the New Version of the Laser-Optical Disdrometer, OTT Parsivel2, J. Atmos. Ocean. Technol., 31, 1276-1288, doi:10.1175/JTECH-D13-00174.1, 2014.
Uijlenhoet, R. and Sempere Torres, D.: Measurement and parameterization of rainfall microstructure, J. Hydrol., 328, 1-7, doi:10.1016/j.jhydrol.2005.11.038, 2006.

Ulbrich, C. W.: Natural variations in the analytical form of the raindrop-size distribution, J. Climate Appl. Meteor., 22, 17641775, 1983.

Ulbrich, C. W.: The Effects of Drop Size Distribution Truncation on Rainfall Integral Parameters and Empirical Relations, J. Climate Appl. Meteor., 24, 580-590, 1985.

Yuter, S. E., Kingsmill, D. E., Nance, L. B., and Löffler-Mang, M.: Observations of precipitation size and fall speed characteristics within coexisting rain and wet snow, J. Appl. Meteorol. Climatol., 45, 1450-1464, doi:10.1175/JAM2406.1, 2006. 